\title{
EFFECTS OF HOT STREAK SHAPE ON ROTOR HEATING IN A HIGH-SUBSONIC SINGLE-STAGE TURBINE
}

\author{
Daniel J. Dorney \\ Virginia Commonwealth University \\ Department of Mechanical Engineering \\ Richmond, VA, USA \\ Karen L. Gundy-Burlet \\ NASA Ames Research Center \\ Computational Physics \& Simulations Branch \\ Moffett Field, CA, USA
}

\begin{abstract}
Experimental data have shown that combustor temperature non-uniformities can lead to the excessive heating of first-stage rotor blades in turbines. This heating of the rotor blades can lead to thermal fatigue and degrade turbine performance. The results of recent studies have shown that variations in the circumferential location (clocking) of the hot streak relative to the first-stage vane airfoils can be used to minimize the adverse effects of the hot streak. The effects of the hot streak/airfoil count ratio on the heating patterns of turbine airfoils have also been evaluated. In the present investigation, three-dimensional unsteady Navier-Stokes simulations have been performed for a single-stage highpressure turbine operating in high subeonic flow. In addition to a simulation of the baseline turbine, simulations have been performed for circular and elliptical hot streaks of varying sizes in an effort to represent different combustor designs. The predicted results for the baseline simulation show good agreement with the available experimental data. The results of the hot streak simulations indicate: that a) elliptical hot streaks mix more rapidly than circular hot streaks, b) for small hot streak surface area the average rotor temperature is not a strong function of hot streak temperature ratio or shape, and c) hot streaks with larger surface area interact with the secondary flows at the rotor hub endwall, generating an additional high temperature region.
\end{abstract}

\section{NOMENCLATURE}

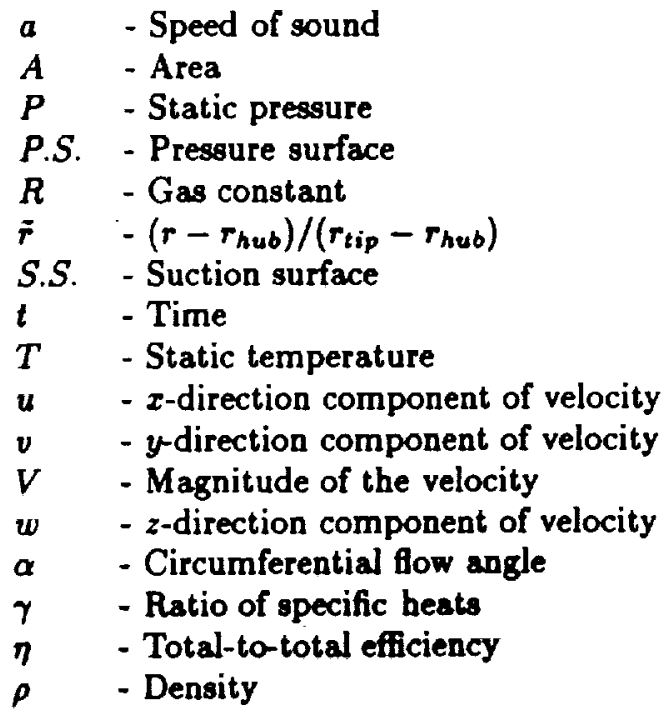

\section{SUBSCRIPTS}

$$
\begin{array}{ll}
c r & \text { - Critical value } \\
\text { hs } & \text { - Hot streak } \\
t & \text { - Stagnation quantity } \\
1 & \text { - Vane inlet quantity } \\
4 & \text { - Exit duct quantity } \\
\infty & \text { - Free stream quantity }
\end{array}
$$

\section{OTHER SYMBOL}

(i) - Time-averaged value 


\section{INTRODUCTION}

Turbine inlet temperature is one of the critical parameters affecting engine operation. Thermal fatigue of vanes and blades is further exacerbated by temperature non-uniformities (hot streaks). The migration of hot streaks through turbines has been simulated by many researchers including Krouthen and Giles (1990), Rai and Dring (1990), Takahashi and Ni $(1990,1991)$, Dorney et al. $(1992,1993,1996)$, Gundy and Dorney (1997), and Shang et al. (1996). For an extensive survey of research into hot streaks, see Dorney et al. (1999). While these numerical simulations have produced significant insights into the mechanisms controlling hot streak migration, there is still a significant amount of research needed to formulate design criteria for minimizing the adverse effects of hot streaks. Most simulations have been performed at low-speed conditions, but additional physics come into play at actual operating conditions.

Some of the earliest experimental investigations of hot streaks were performed on a high-speed turbine by researchers at NASA Glenn Research Center (Whitney et al., 1980; Schwab et al., 1983; Stabe et al., 1984). The goal of these experiments was to study the effects of typical nonuniform inlet radial temperature profiles on the performance of axial turbines. The inlet radial temperature profile in the experiment was produced using a Combustor Exit Radial Temperature Simulator (CERTS) inlet which injected cool air through circumferential slots in the hub and tip endwalls upstream of the vane. In addition to a total temperature profile, a total pressure profile was generated using the CERTS inlet.

The focus of the present effort has been to study the effects of hot streak shape on the heating of firststage turbine rotors. The goal of work is to identify hot streak shapes (i.e., combustor designs) which minimize rotor temperatures. The NASA CERTS geometry was chosen as the test article for the current simulations because the flow conditions are respresentative of an actual engine environment. Previous research efforts have focused on circular hot streaks (e.g., Takahashi et al., 1990; Dorney et al., 1992) to be consistent with the experiments of Butler et al. (1989). Actual engines, however, tend to contain hot streaks which are more elliptical in nature (Suo, 1985). Therefore, simulations have been performed using three different sizes for a circular hot streak superimposed on the CERTS profile, as well as for two different sizes of an elliptical hot streak superimposed on the CERTS profile. Time-averaged and unsteady temperature data have been analyzed, and comparisons made with available experimental data.

\section{NUMERICAL METHOD}

The governing equations considered in this study are the time dependent, three-dimensional Reynolds-averaged Navier-Stokes equations. The viscous fluxes are simplified by incorporating the thin layer assumption (Baldwin and Lomax, 1978). In the current study, viscous terms are retained in the direction normal to the hub and shroud surfaces, and in the direction normal to the blade surfaces. The numerical algorithm used in the threedimensional computational procedure consists of a time-marching, implicit, finite-difference scheme. The procedure is third-order spatially accurate and second-order temporally accurate. The inviscid fluxes are discretized according to the scheme developed by Roe (1981). The viscous fluxes are calculated using standard central differences. An approximate-factorization technique is used to compute the time rate changes in the primary variables. In addition, Newton sub-iterations are used at each global time step to increase stability and reduce linearization errors. For all cases investigated in this study, one Newton sub-iteration was performed at each time step. To extend the equations of motion to turbulent flows, an eddy viscosity formulation is used. The turbulent viscosity is calculated using the two-layer Baldwin-Lomax (1978) algebraic turbulence model.

The Navier-Stokes analysis uses $\mathrm{O}$ - and H-type zonal grids to discretize the flow field and facilitate relative motion of the airfoils (see Fig. 8). The O-grids are body-fitted to the surfaces of the airfoils and generated using an elliptic equation solution procedure. They are used to properly resolve the viscous flow in the blade passages and to easily apply the algebraic turbulence model. Algebraically generated H-grids are used to discretize the remainder of the flow field.

The code has been parallelized using the Message Pasoing Interface (MPI) library. In the current implementation, the solution is decomposed by blade row, blade passage, or individual grid depending on the number of processors available.

Further details on the numerical procedure can be found in Dorney et al. $(1992,1993,1995)$ and Rai (1987). 


\section{Boundary Conditions}

The theory of characteristics is used to determine the boundary conditions at the inlet and exit of the computational domain. At the inlet, the total pressure, total temperature and the circumferential and radial flow angles are specified as a function of the radius. The upstream running Riemann invariant is extrapolated from the interior of the computational domain.

For simulations containing inlet hot streaks, the flow variables within the hot streak must be modified. Within the hot streak the inlet flow variables used to define the specified boundary conditions can be written as

$$
\begin{array}{ll}
u_{h s}=u_{\infty} \sqrt{T_{h s} / T_{\infty}} & v_{h s}=v_{\infty} \sqrt{T_{h s} / T_{\infty}} \\
w_{h s}=w_{\infty} \sqrt{T_{h s} / T_{\infty}} & P_{h s}=P_{\infty} \\
a_{h s}=a_{\infty} \sqrt{T_{h s} / T_{\infty}} & \rho_{h s}=\rho_{\infty} /\left(T_{h s} / T_{\infty}\right)
\end{array}
$$

where $T_{h s}$ is the temperature within the hot streak and $T_{\infty}$ is the temperature of the undisturbed inlet flow. The static and total pressure within the hot streak are assumed to be equal to that of the undisturbed inlet flow (Butler et al., 1989). In the current investigation two different temperature profile configurations have been implemented. The first configuration used the original CERTS profiles to allow comparisons with experimental data, while in the second set of simulations a discrete hot streak was superimposed on the CERTS profiles to more realistically model engine conditions.

At the exit the circumferential and radial velocity components, entropy, and the downstream running Riemann invariant are extrapolated from the interior of the computational domain. The preseure ratio, $P_{4} / P_{81}$, is specified at mid-span of the computational exit and the pressure values at all other radial locations are obtained by integrating the equation for radial equilibrium. Periodicity is enforced along the outer boundaries of the H-grids in the circumferential direction.

No-slip boundary conditions are enforced at the hub and tip end walls, and along airfoil surfaces. It is assumed that the normal derivative of the pressure is zero at solid wall surfaces, and that the walls are adiabatic.

The flow variables at zonal boundaries are explicitly updated after each time step by interpolating values from the adjacent grid.

\section{GEOMETRY AND GRID}

The CERTS test turbine was a 0.767 scale rig modeling the first stage of a two-stage core turbine designed for a modern high bypass ratio engine. The design criteria for the model were to accommodate the high-work, low flow characteristics for this type of turbine and achieve a subsonic design with reasonable blade height. The vane has a constant section (untwisted), and was designed for a constant exit flow angle of $75^{\circ}$ from axial. The rotor leading edge was designed to accept the vane exit flow with either zero or small negative incidence. The rotor exit was designed for free vortex flow. The design conditions for the turbine are shown in Table 1.

\begin{tabular}{|c|c|}
\hline Inlet total temp & $672.2 \mathrm{~K}$ \\
Inlet total pres & $3.103 \times 10^{5} \mathrm{~Pa}$ \\
Mass flow & $6.130 \mathrm{~kg} / \mathrm{s}$ \\
Specific work & $1.229 \times 10^{5} \mathrm{~J} / \mathrm{kg}$ \\
Rotational speed & $11,373 \mathrm{RPM}$ \\
Total pressure ratio & 2.360 \\
\hline
\end{tabular}

Table 1: CERTS flow conditions.

The inlet radial temperature profile in the experiments was produced using the CERTS inlet which injected cool air through circumferential slots in the hub and tip endwalls upstream of the vane(see Fig. 1). In addition to a total temperature profile, a total pressure profile was generated using the CERTS inlet (see Fig. 2). The ratio of the maximum total temperature to the average total temperature was approximately 1.05 , and the ratio of maximumto-minimum total temperature was approximately 1.20. The peak Mach number in the turbine was in the high subeonic range, $\approx 0.92$.

A total of six computations have been performed in this investigation. In the first simulation (designated $\mathrm{N} 1$ ) the baseline CERTS flow conditions were sun to facilitate comparisons with the available experimental data. Three simulations were performed in which discrete circular hot streaks of varying size were added to the model, and two simulations were performed in which discrete elliptical hot streaks of varying size were added to the model. Table 2 summarizes the conditions associated which each simulation. Figures 3 to 7 illustrate the shapes of the hot streaks, as well as their radial locations. Based on the results of previous studies (e.g., Dorney and Gundy-Burlet, 1996) the hot streaks were aligned with the first-stage vanes to minimize rotor pressure- 
surface heating.

\begin{tabular}{|c|c|c|c|c|}
\hline Run & HS Shape & $\begin{array}{l}\text { Minor Axis } \\
(\mathrm{cm})\end{array}$ & $\begin{array}{l}\text { Major Axis } \\
\text { (cm) }\end{array}$ & $\frac{T, T_{0}}{T_{\infty}}$ \\
\hline $\mathrm{Nl}$ & - & - & - & - \\
\hline $\mathrm{Cl}$ & Circular & 0.84 & 0.84 & 1.2 \\
\hline $\mathrm{C} 2$ & Circular & 1.68 & 1.68 & 1.2 \\
\hline $\mathrm{C} 3$ & Circular & 2.52 & 2.52 & 1.2 \\
\hline E1 & Elliptical & 1.00 & 0.50 & 1.5 \\
\hline E2 & Elliptical & 1.25 & 0.50 & 1.5 \\
\hline
\end{tabular}

Table 2: Simulation test conditions.

The experimental configuration has 26 vane airfoils and 48 rotor airfoils. A three-dimensional computation of the flow through the complete turbine configuration would be prohibitively expensive. To reduce the cost of the computation, the number of vanes in the first row was decreased to 24 and the size of the vane was increased by a factor of $26 / 24$ to maintain the same blockage. In the baseline simulation (case $\mathrm{N} 1$ ) a 1 -vane/2-rotor airfoil count ratio was used, while in the simulations with the superimposed hot streaks a 2-vane/4-rotor ratio was used to allow a more realistic configuration of one hot streak for every other vane passage. The rotor tip was allowed to scrape along the case (i.e., zero tip clearance) in this simulation.

Two views of the grids used to discretize the flow field are shown in Figs. 7 and 8 (every other grid point in Fig. 8 has been removed for clarity). The O-grids each contain 121 points in the wrap-around direction, 31 points in the surface-normal direction and 51 points in the radial direction. The $\mathrm{H}$-grids for the vane and rotor regions each contain 86 points in the axial direction, 51 points in the circumferential direction and 51 points in the radial direction. The H-grid used to discretize the outlet region of the turbine stage contains 14 points in the axial direction, 41 points in the circumferential direction and 51 points in the radial direction. The axial and circumferential grid dimensions necessary to resolve convected wakes and hot streaks were determined using a two-dimensional analysis. The average values of $y^{+}$, the non-dimensional distance of the first grid line above the surface, were 1.5 for the airfoils and 3.0 for the endwalls. The total number of grid points used to discretize the turbine flow field for the baseline case was approximately 1.27 million, while the simulations with a superimposed hot streak utilized approximately 2.54 million grid points.
The computations were performed on eight 250 $\mathrm{MHz}$ processors of a Silicon Graphics Origin 2000 computer located at NASA Ames Research Center. Each computation required approximately $6 \times 10^{-5}$ secs/grid point/iteration computation time (i.e., each iteration takes approximately 28 seconds wall clock time). The computations were each run for 20 cycles using 1 sub-iteration per time step and 6000 time steps per cycle. Here, a cycle is defined as the time it takes a rotor to travel a circumferential distance equal to 1 vane pitch. The periodicity of the hot streak solutions was verified by plotting temperature traces at various locations on the airfoil surfaces. Figures 9 and 10 show example temperature traces near midspan at the rotor leading edge for cases $\mathrm{Cl}$ and $\mathrm{E} 2$, respectively. The variations of the temperature due to the vane wake and the hot streak are visible in these figures.

\section{NUMERICAL RESULTS}

The Mach number at the inlet to the vane is approximately 0.14 and the inlet flow is assumed to be axial. The rotor rotational speed was 11,373 rpm. The free stream Reynolds number was 197,000 based on the rotor axial chord. A pressure ratio of $P_{4} / P_{t 1}=0.385$ was calculated from the experimental data based on the mid-span inlet total pressure and the static pressure in the rotor trailing edge plane.

\section{Case N1 - CERTS Only}

Figures 11 to 13 show comparisons between the predicted and experimental time-averaged critical velocity ratio distributions, where the critical velocity ratio is defined as

$$
\bar{V} / V_{\mathrm{cr}}=\bar{V} / \sqrt{\frac{2 \gamma}{\gamma+1} R \bar{T}_{t}}
$$

and the velocity is based on the isentropic Mach number. There is generally good agreement between the predicted and experimental results, with small differences evident near peak suction.

Figure 14 contains the predicted and experimental radial profiles of circumferentially-averaged flow angle $2-1 / 2$ chord lengths downstream of the rotor. Also included in Fig. 14 is the design-intent flow angle distribution. Both the predicted and experimental results indicate underturning near midspan. A previous study traced the underturning to a large secondary flow region near the hub endwall in the 
rotor passage (Dorney and Schwab, 1995). In general, there is good agreement between the predicted and experimental data from $20 \%$ span to $90 \%$ span. The discrepancy near the casing is probably due to the lack of modeling the clearance gap. Near the hub endwall there are discrepancies between the numerical and experimental angles. The differences are due to the extent of the secondary flows in the rotor passage being greater in the experiments than in the simulations.

Figure 15 shows the predicted and experimental total pressure distributions $2-1 / 2$ chord lengths downstream of the rotor. There is good agreement from $30 \%$ to $90 \%$ span. The discrepancies in the tip region are due to the differences in the experimental $(0.4 \%)$ and modeled $(0.0 \%)$ tip clearances, while the variations near the hub are due to the larger secondary flows in the experiments.

Figure 16 contains the predicted and experimental total temperature distributions $2-1 / 2$ chords downstream of the rotor. The predicted values show close agreement with the experimental data.

The experimentally determined time-averaged efficiency for this turbine was $\eta=0.883$, while the predicted value was $\eta=0.886$, where the efficiency is determined as:

$$
\eta=\frac{\left(P_{t 4} / P_{t 1}\right)^{\frac{\gamma-1}{\gamma}}-1.0}{T_{t 1} / T_{t 4}-1.0}
$$

\section{Cases with CERTS and Circular Hot Streak}

Although the experimental study using the CERTS contained a radial temperature profile, discrete circuler hot streaks were added at the inlet to the turbine to represent a more realistic engine temperature distribution.

Figures 17 to 19 contain contours of time-averaged static temperature on the pressure surface of the rotor for cases $\mathrm{Cl}$ to $\mathrm{C} 3$, respectively. Increasing the size of the hot streak causes an increased thermal load on the rotor pressure surface in spite of aligning the hot streak with the first-stage vane. The extent of the high-temperature region increases in both the axial and radial directions. The time-averaged temperature on the suction surface (see Figs. 20 to 22) also elevates as the size of the hot streak is increased, although the main high-temperature region remains confined to a relatively narrow region by the hub and tip secondary flows. As the size of the hot streak is increased, a second high temperature region develope within the hub endwall secondary flows. Figure 23 shows the integrated time-averaged temperature on the surface of the rotor as a function of hot streak area. Starting from case NI (no hot streak) the average rotor temperature increases nearly linearly with hot streak area.

Figures 24 to 26 show radial profiles of the timeaveraged absolute total temperature at the inlet of the vane, the exit of the vane and exit of the rotor, respectively. Note, the average profiles include both vane passages. The profile at the vane inlet reflects the differences in the relative size of the hot streaks. As the hot streak is convected through the vane passage the location of the peak temperature moves radially from $40 \%$ span to approximately $50 \%$ span (see Fig. 25). The radial movement of the hot streak is probably enhanced by the hub secondary flows, which extend to nearly $20 \%$ of the span. In addition, as the size of the hot streak is increased the temperature near the hub endwall increases dramatically. The hot streak is mixed out by the time the flow exits the rotor passage, although the profiles still reflect the temperature increases associated with increasing the area of the hot streak.

Figures 27 to 29 contain radial profiles of the timeaveraged absolute total pressure at the inlet of the vane, the exit of the vane and exit of the rotor, respectively. The increased hot streak area does not significantly alter the total pressure profile at the vane exit (see Fig. 28). Small variations can be observed in the total pressure profile at the rotor exit near $20 \%$ span, where the total pressure increases with increasing hot streak area. Overall, the losses are not significantly altered by increasing the area of the hot streak.

Radial profiles of the time-averaged absolute circumferential flow angle at the exit of the vane and the exit of the rotor are shown in Figs. 30 and 31 . The absolute flow angle distributions at the vane exit are nearly independent of the hot streak area, although the hot streak cases indicate more flow turning than with only the CERTS profile. This is probably due to the alignment of the hot streak with the vane leading edge, which causes the hot fluid to mix with the vane wake. More significant flow angle variations (locally on the order of 5 degrees) are observed at the exit of the rotor. The locations of largest flow angle variations coincide the position of the mixed out hot streak. In general, the flow angle increases under the influence of the hot streak.

\section{Cases with CERTS and Elliptical Hot Streak}

Figures 32 and 33 contain contours of timeaveraged static temperature on the pressure surface 
of the rotor for cases E1 and E2. Similar to the cases $\mathrm{Cl}$ to $\mathrm{C} 3$, the pressure surface of the rotor displays considerable heating as the area of the hot streak is increased. However, dissimilar to the circular hot streaks, the elliptical hot streaks do not uniformly heat the pressure surface as the area increases. Two distinct high temperature regions develop, one extending from approximately $45 \%$ to $55 \%$ of the span and one ranging from approximately $75 \%$ to $85 \%$ of the span. Unlike the circular hot streak results, the high temperature region on the suction surface (see Figs. 34 and 35) expands as the area of the hot streak is increased. The temperature within the hub secondary flows also increases as the size of the hot streak is increased. Figure 23 shows the integrated time-averaged temperature on the surface of the rotor as a function of hot streak area. For small values of area the average surface temperature associated with the elliptical hot streaks track close to the those for the circular hot streaks. As the area increases, however, the average temperature of the rotor increases more rapidly for the elliptical hot streaks. This behavior is caused by the elliptical hot streaks having a greater temperature ratio than the circular hot streaks (see Table 2).

Figures 36 to 38 show radial profiles of the timeaveraged absolute total temperature at the inlet of the vane, the exit of the vane and exit of the rotor, respectively. The relatively high temperature of the hot streaks is evident at the inlet of the vane. The hot streak displays more mixing at the exit of the vane compared to circular hot streak simulations. The enhanced mixing is generated by two sources. First, the hot streak temperature ratio $\left(T_{h_{0}} / T_{\infty}=1.5\right)$ is greater in the elliptical hot streak simulations. The larger gradient between the hot streak and surrounding core flow increases the mixing. The second source of enhanced mixing is the shape of the hot streak. Elliptical hot streaks will have the more circumference per unit area (circles have the minimum circumference per unit area), thus exposing more of the hot streak to the cooler surrounding fluid. The hot streak is fully mixed at the exit of the rotor, although the effects of the increased hot streak area are still visible.

Radial profiles of the time-averaged absolute to tal preasure at the inlet of the vane, the exit of the vane and exit of the rotor, respectively, are shown in Figs. 39 to 41 . Increasing hot streak area has little effect on the total pressure profiles at all three locations.

Figures 42 and 43 illustrate radial profiles of the time-averaged absolute circumferential flow angle at the exit of the vane and the exit of the rotor. The flow angles at the exit of the vane are nearly identical for the two hot streak cases, and both hot streak simulations show more flow turning through the vane than for the case with the CERTS profile alone. At the exit of the rotor the flow angle distributions are only weakly dependent on the hot streak area. The simulations containing a hot streak do not show the flow angle deficit near midspan observed in the case with the CERTS profile alone. As discussed above, the origin of the flow angle deficit is the strong rotor endwall secondary flows (e.g., Fig. 34). Therefore, the hot streak is affecting the strength of the secondary flows (which can be observed by comparing Figs. 34 and 35).

\section{CONCLUSIONS}

A series of three-dimensional unsteady NavierStokes simulations have been performed for the CERTS turbine to study the effects of hot streak shape on the migration characteristics of combustor temperature distortions. The predicted results for the baseline CERTS case exhibit good agreement with the available data. The following conclusions have been made based on the results of the hot streak simulations:

- Elliptical hot streaks tend to mix out more rapidly than circular hot streaks, in part because of increased surface area exposed to the cooler surrounding fluid.

- For small hot streak surface area the average rotor surface temperature is not a strong function of hot streak temperature ratio or shape.

- As the hot streak surface area increases, the rotor surface will heat more rapidly at higher hot streak temperature ratios.

- Hot streaks with larger surface area interact with the secondary flows at the rotor hub endwall, generating an additional high temperature region.

\section{REFERENCES}

Baldwin, B. S., and Lomax, H., 1978, "Thin Layer Approximation and Algebraic Model for Separated Turbulent Flow," AIAA Paper 78-257, Huntsville, AL, January.

Butler, T. L., Sharma, O. P., Joslyn, H. D., and 
Dring, R. P., 1989, "Redistribution of an Inlet Temperature Distortion in an Axial Flow Turbine Stage," AIAA Journal of Propulsion and Power, Vol. 5, January-February, pp. 64-71.

Dorney, D. J., Davis, R. L., Edwards, D. E., and Madavan, N. K., 1992, "Unsteady Analysis of Hot Streak Migration in a Turbine Stage," AIAA Journal of Propulsion and Power, Vol. 8, No. 2, pp. 520-529.

Dorney, D. J., and Davis, R. L., 1993, "Numerical Simulation of Turbine 'Hot Spot' Alleviation Using Film Cooling," AIAA Journal of Propulsion and Power, Vol. 9, No. 3, pp. 329-336.

Dorney, D. J., and Schwab, J. R., 1995, "Unsteady Numerical Simulations of Radial Temperature Profile Redistribution in a Single-Stage Turbine," ASME Journal of Turbomachinery, Vol. 118, No. 4, October, 1996, pp. 783-791.

Dorney, D. J., and Gundy-Burlet, K. L., 1996, "Hot Streak Clocking Effects in a 1-1/2 Stage Turbine," AIAA Journal of Propulsion and Power, Vol.12, No. 3, pp. 619-620.

Dorney, D. J., Gundy-Burlet, K. L., and Sondak, D. L., 1999, "Survey of Hot Streak Experiments and Simulations," International Journal of Turbo and Jet Engines, Vol. 16, No. 1, pp. 1-15.

Gundy-Burlet, K. L., and Dorney, D. J., 1997, "Influence of 3D Hot Streaks on Turbine Heat Transfer," International Joumal of Turbo and Jet Engines, Vol. 14, No. 3, pp. 123-132.

Krouthen, B., and Giles, M. B., 1990, "Numerical Investigation of Hot Streaks in Turbines," AIAA Journal of Propulsion and Power, Vol. 6, No. 6, pp. 769-776.

Rai, M. M., "Navier-Stokes Simulations of Rotor/Stator Interactions Using Patched and Overlaid Grids", J. Propulsion Power, Vol. 3, No. 5, Sept., pp. 387-396, 1987.

Rai, M. M., and Dring, R. P., 1990, "Navier-Stokes Analysis of the Redistribution of Inlet Temperature Diatortions in a Turbine," AIA A Journal of Propulsion and Power, Vol. 6, pp. 276-282.
Roe, P. L., 1981, "Approximate Riemann Solvers, Parameter Vectors, and Difference Schemes," Journal of Computational Physics, Vol. 43, pp. 357-372.

Schwab, J. R., Stabe, R. G., and Whitney, W. J., 1983, "Analytical and Experimental Study of Flow Through an Axial Turbine Stage with a Nonuniform Inlet Radial Temperature Profile," AIAA Paper 831175, Seattle, WA, June.

Shang, T., and Epstein, A. H., 1996, "Analysis of Hot Streak Effects on Turbine Rotor Heat Load," ASME Paper 96-GT-118, Birmingham, England, June, also to be published in the ASME Journal of Turbomachinery.

Stabe, R. G., Whitney, W. J., Moffitt, T. P., 1984, "Performance of a High-Work Low Aspect Ratio Turbine Tested with a Realistic Inlet Radial Temperature Profile," AlAA Paper 84-1161, Cincinnati, OH, June.

Suo, M., 1985, Turbine Cooling, Aerothermodynamics of Aircraft Engine Components, AIAA Education Series, pp. 275-330.

Takahashi, R. K., and Ni, R. H., 1990, "Unsteady Euler Analysis of the Redistribution of an Inlet Temperature Distortion in a Turbine," AIAA Paper 902262, Orlando, FL.

Takahashi, R. K., and Ni, R. H., 1991, "Unsteady Hot Streak Migration Through a 1-1/2 Stage Turbine," AIAA Paper 91-3382, Sacramento, CA.

Whitney, W. J., Stabe, R. G., and Moffitt, T. P., 1980, "Description of the Warm Core Turbine Facility and the Warm Annular Cascade Facility Recently Installed at NASA Lewis Research Center," NASA TM 81562. 


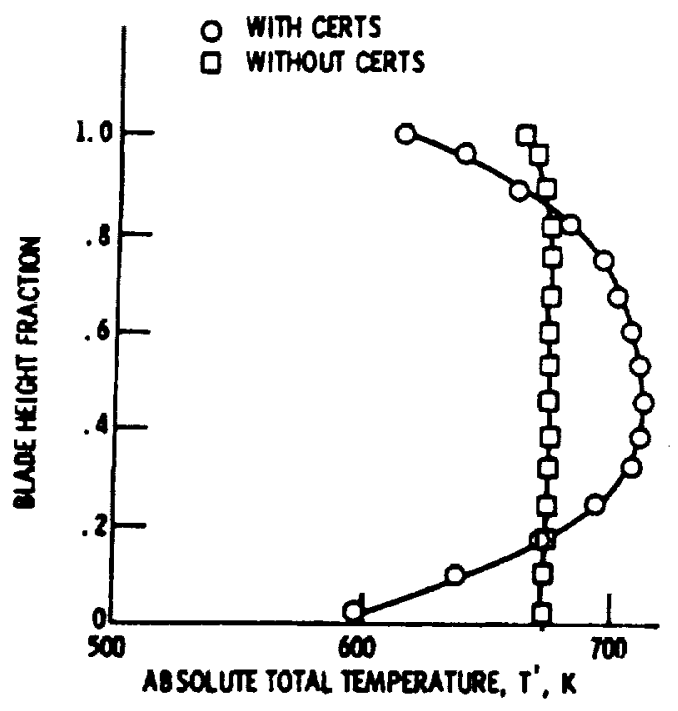

Figure 1: CERTS total temperature profile (Schwab et al., 1983).

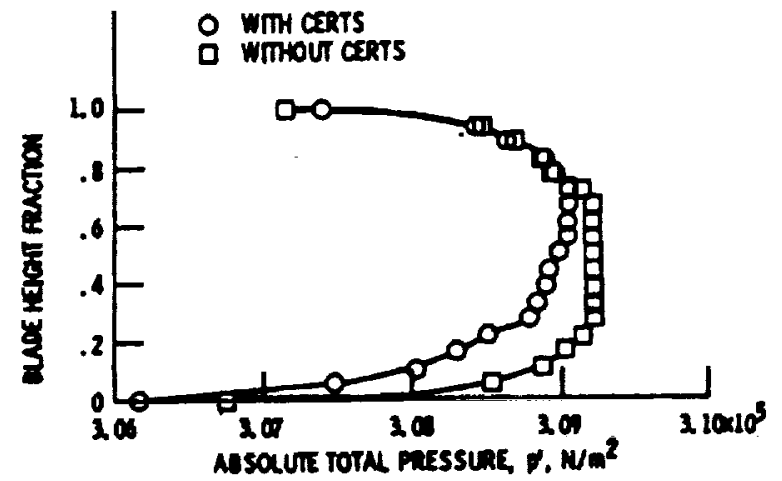

Figure 2: CERTS pressure temperature profile (Schwab et al., 1983).

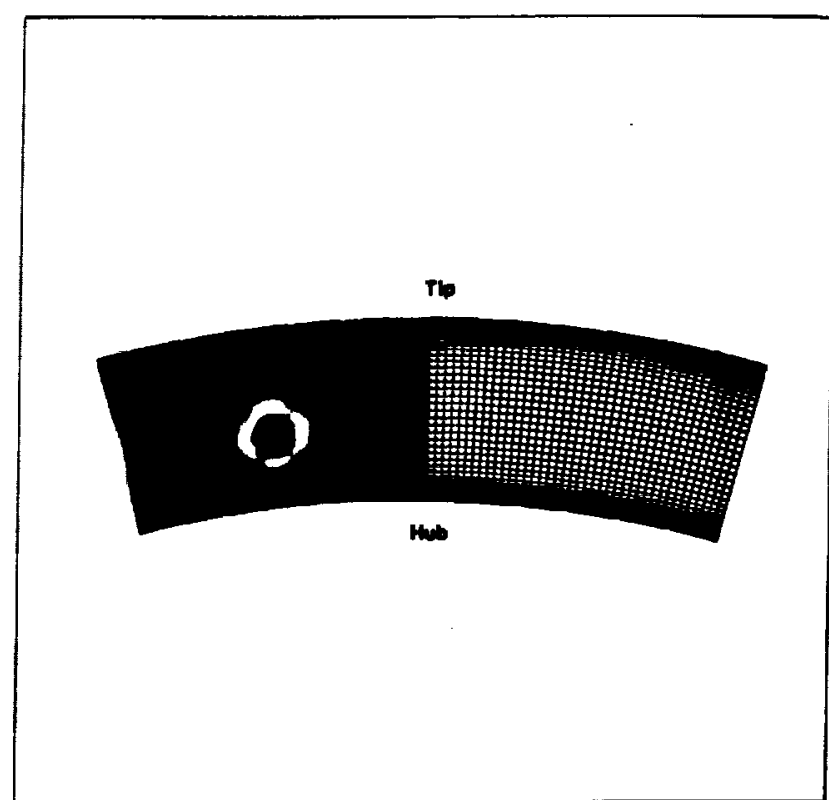

Figure 3: Hot streak profile - Case C1.

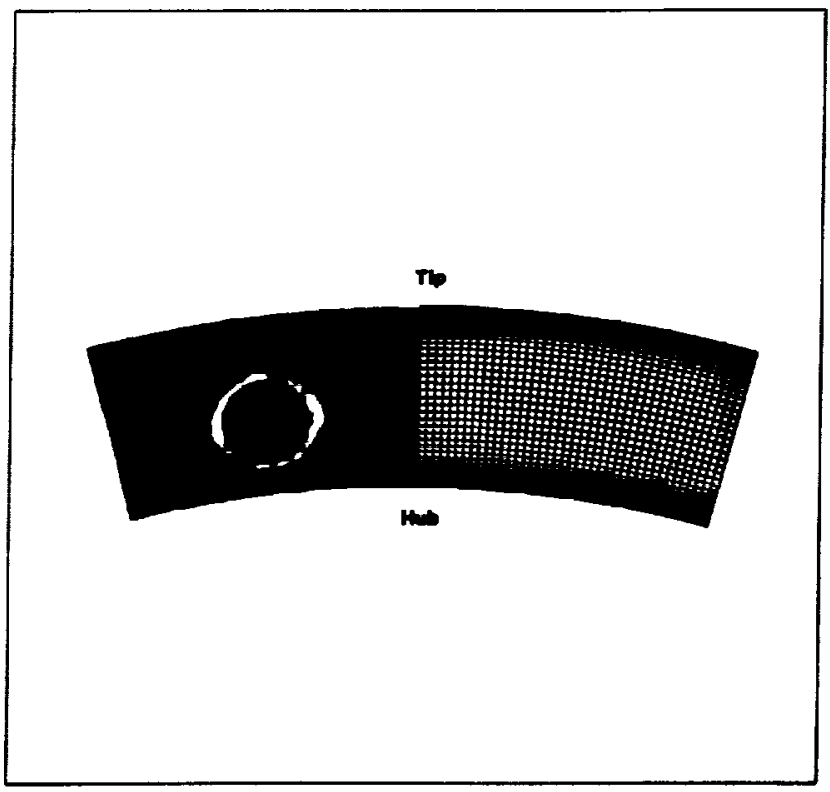

Figure 4: Hot streak profile - Case C2. 


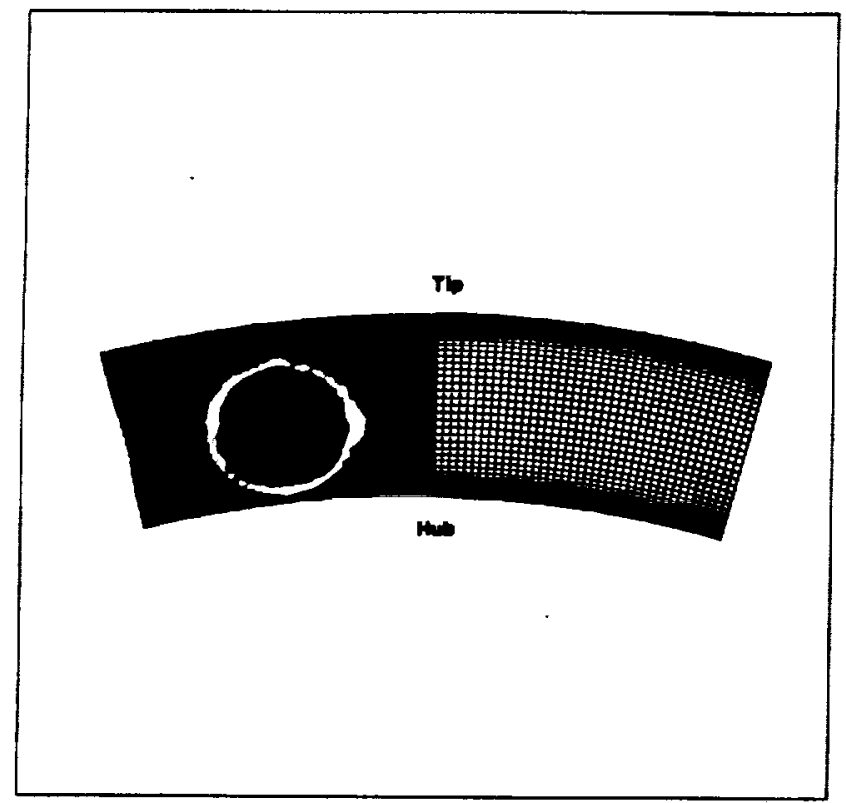

Figure 5: Hot streak profile - Case C3.

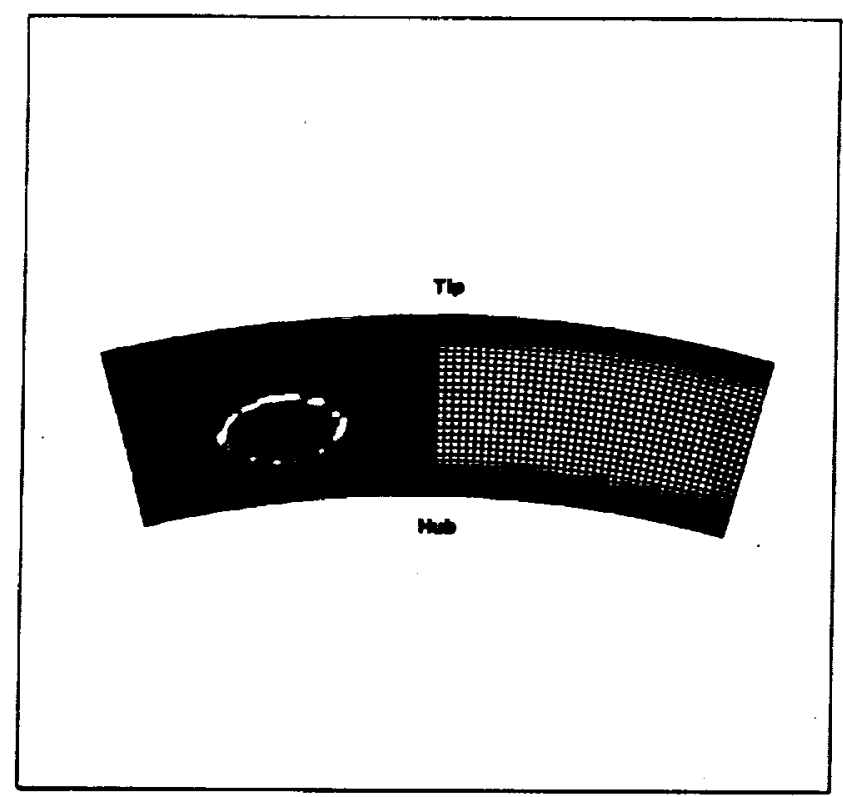

Figure 6: Hot streak profile - Case E1.

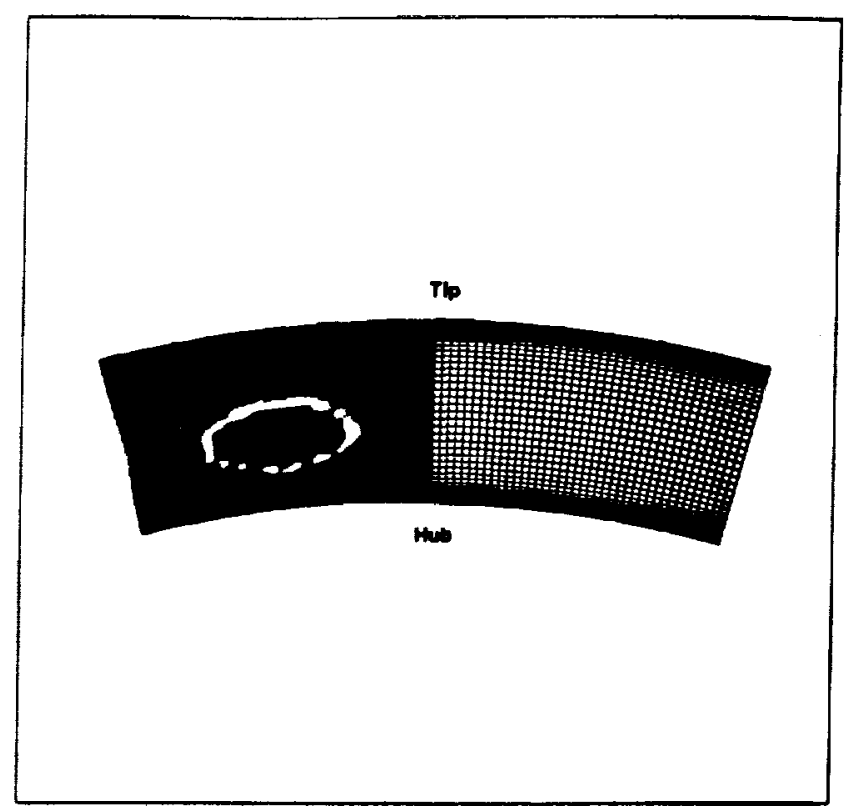

Figure 7: Hot streak profile - Case E2.

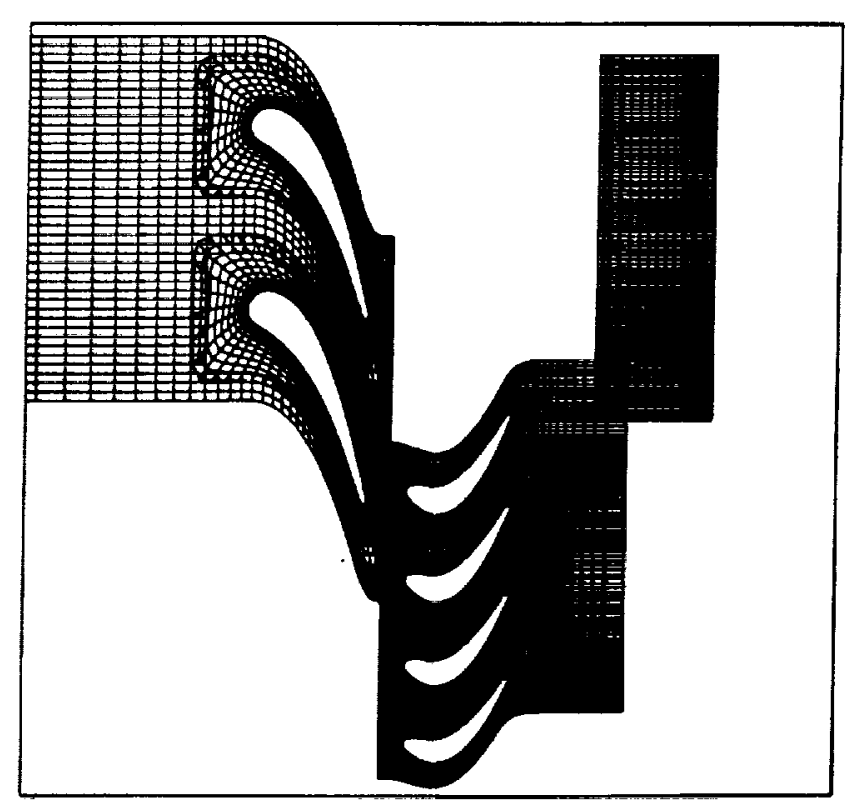

Figure 8: Computational grid spanwise view. 

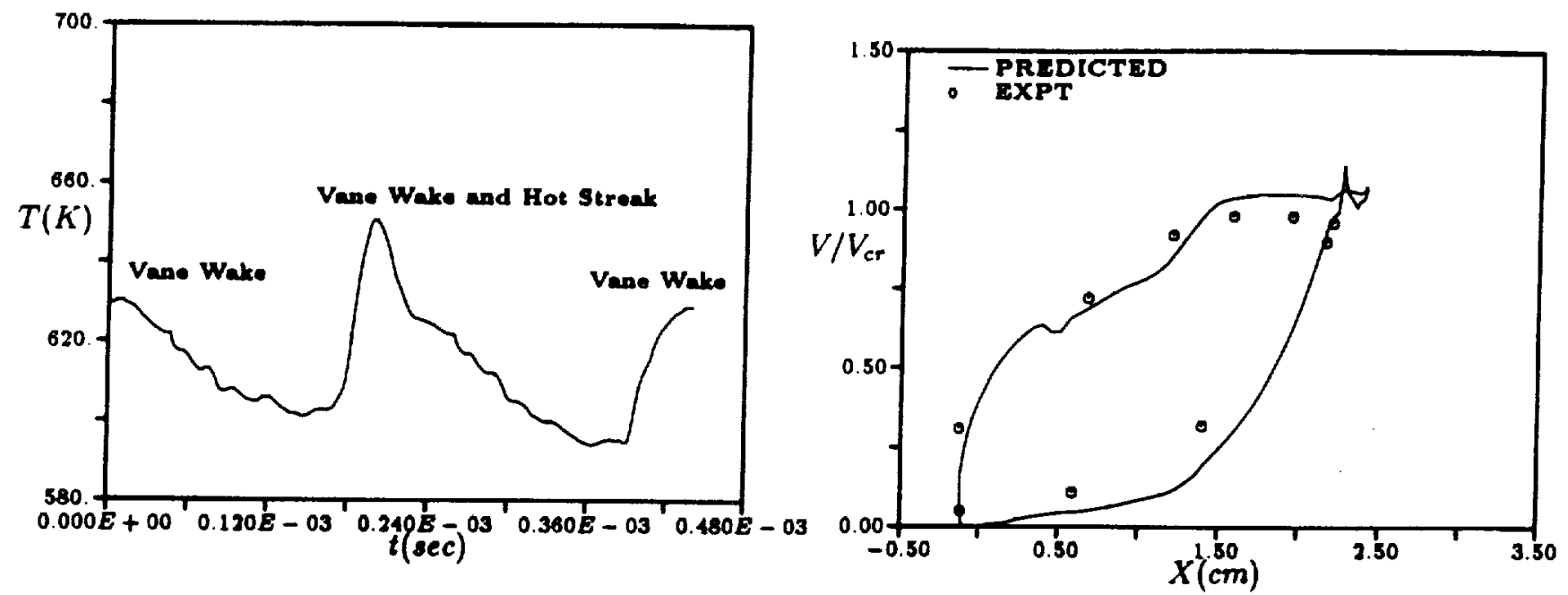

Figure 9: Unsteady temperature history at midspan of the rotor leading edge - Case C1.

Figure 11: Critical velocity ratio at the hub of the vane - Case N1.
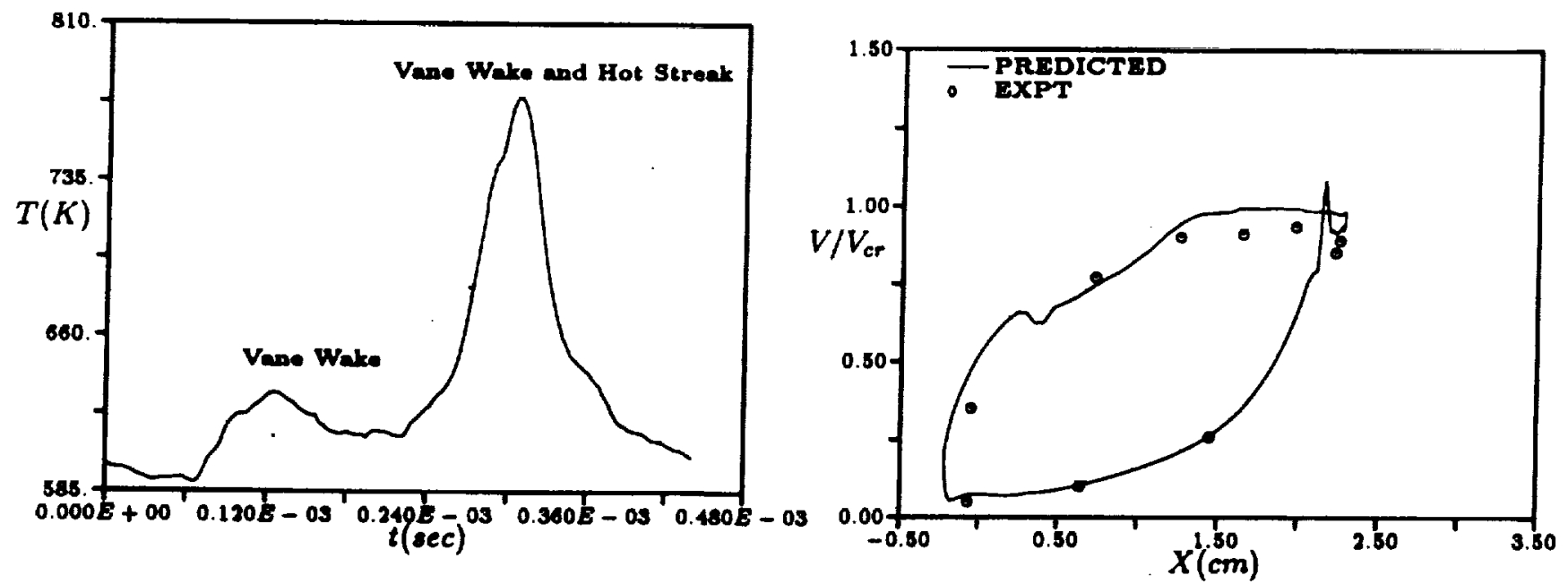

Figure 10: Unsteady temperature history at midspan of the rotor leading edge - Case E2.

Figure 12: Critical velocity ratio at midspan of the vane - Case N1. 


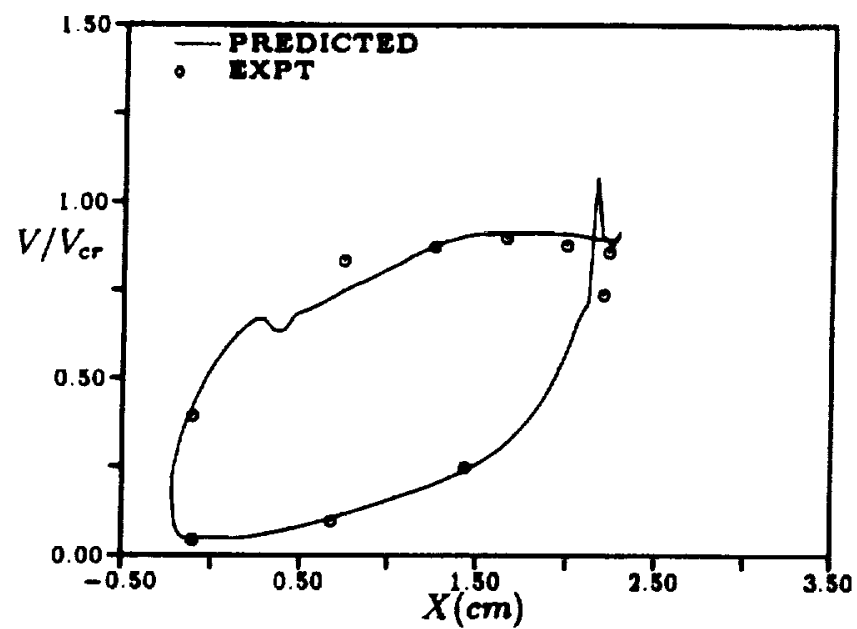

Figure 13: Critical velocity ratio at the tip of the vane - Case N1.

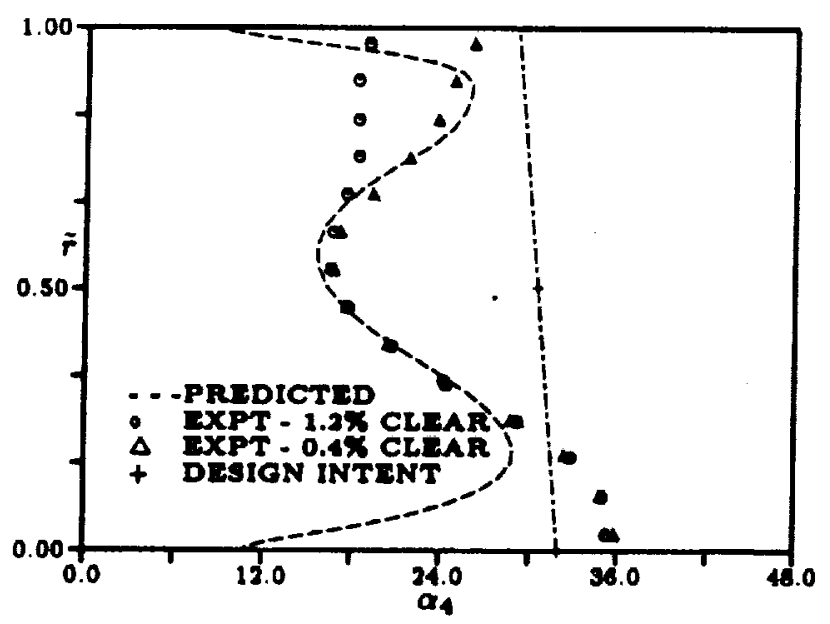

Figure 14: Aboolute circumferential flow angle distribution at the exit of the atage - Case N1.

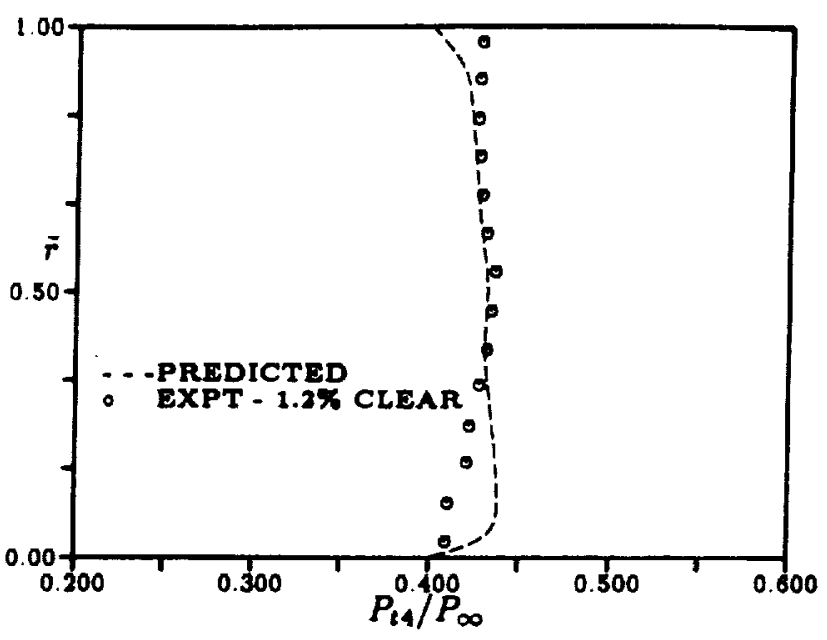

Figure 15: Total pressure distribution at the exit of the stage - Case N1.

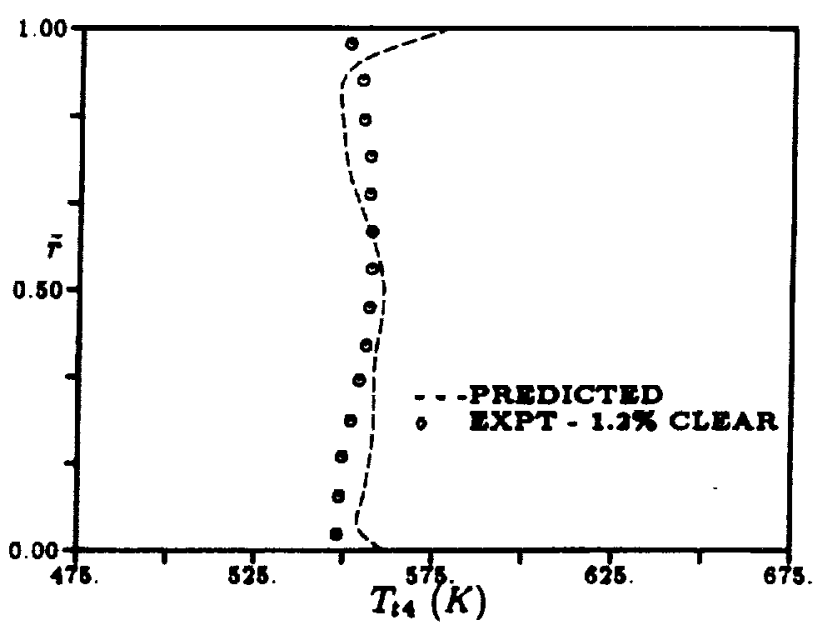

Figure 16: Total temperature distribution at the exit of the stage - Case NI. 


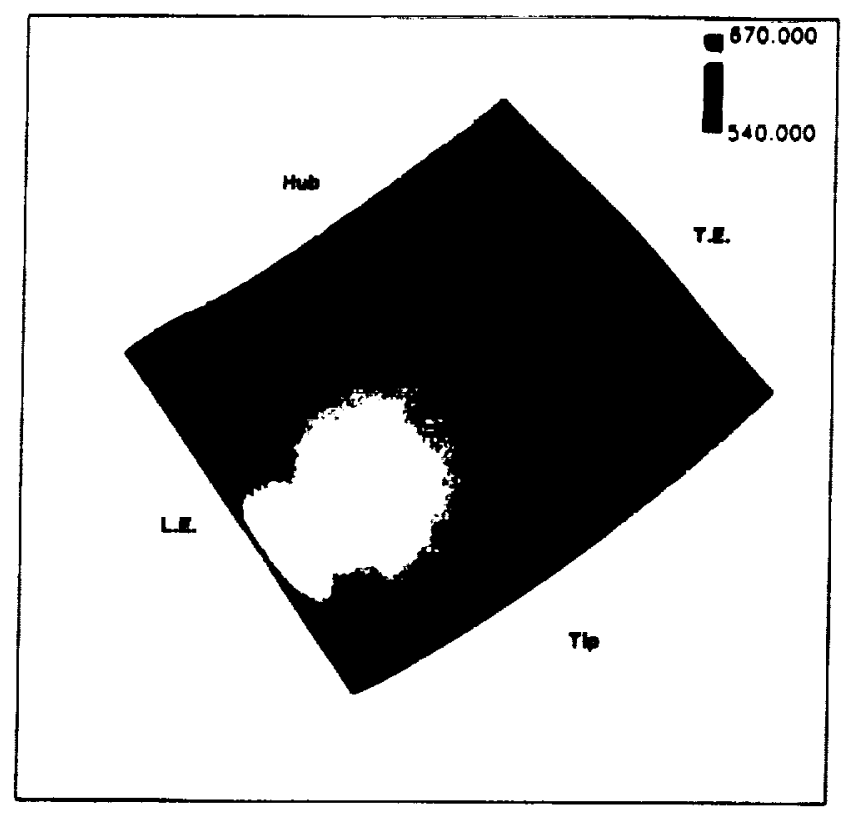

Figure 17: Time-avg. temperature - P.S. - Case C1.

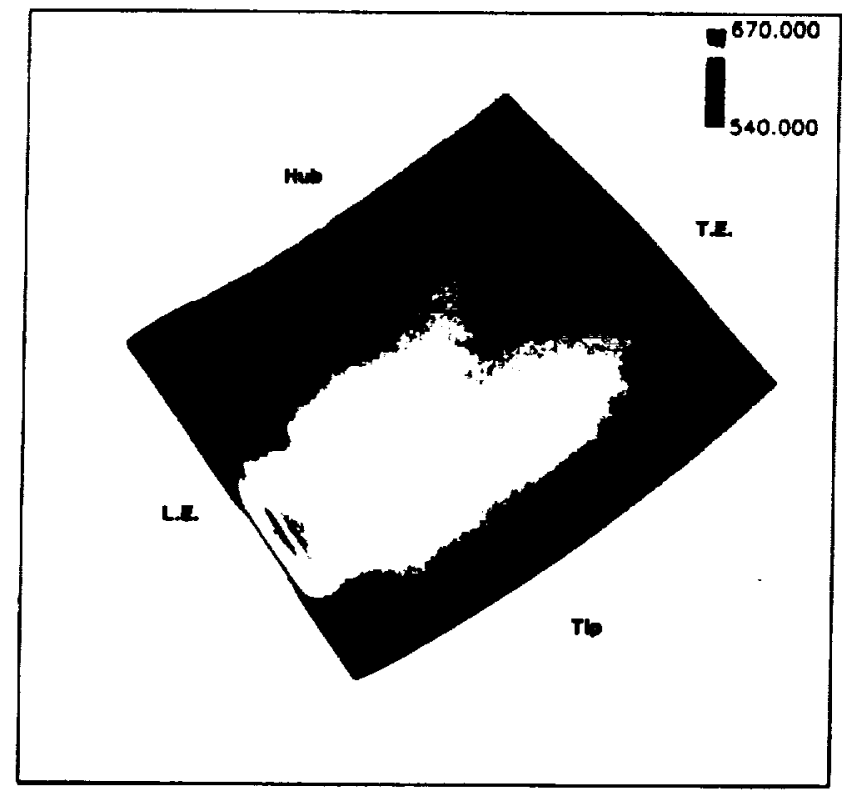

Figure 18: Time-avg. temperature - P.S. - Case C2.

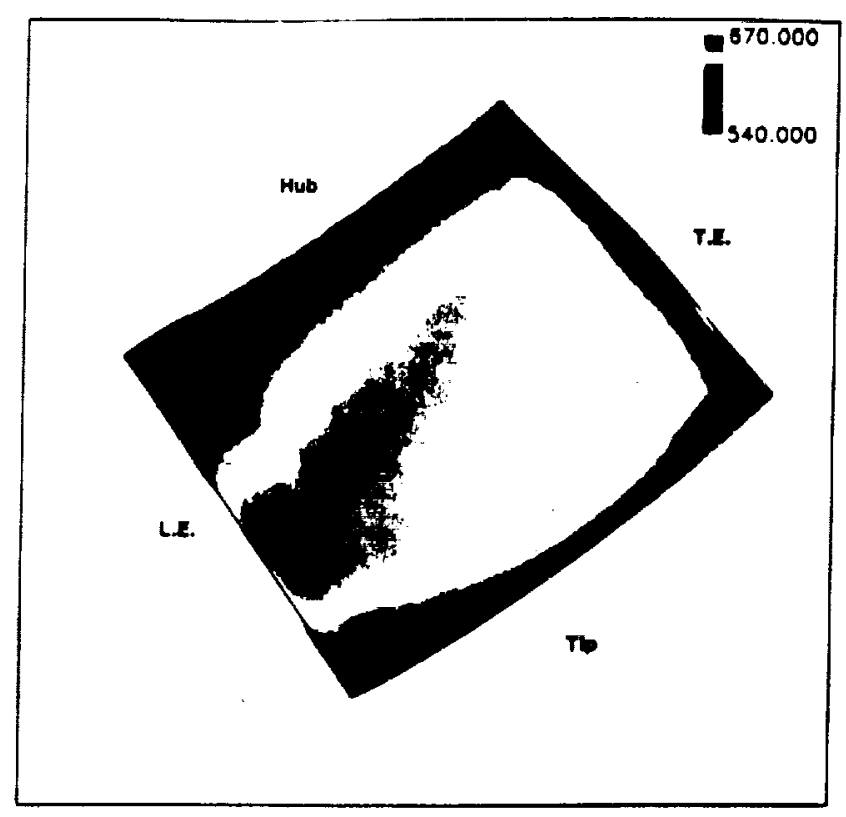

Figure 19: Time-avg. temperature - P.S. - Case C3.

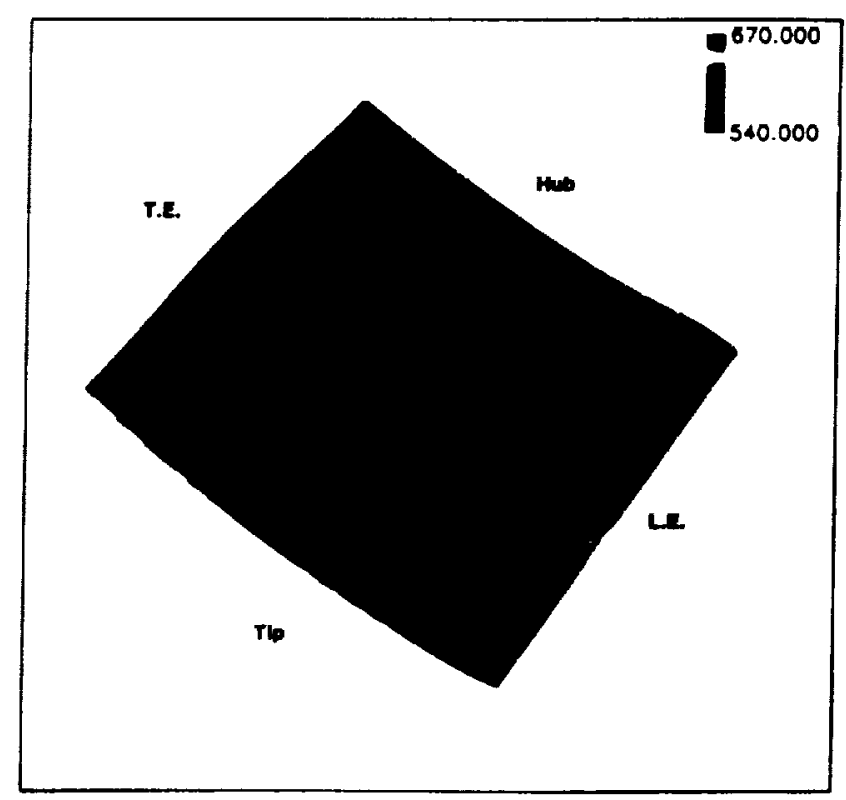

Figure 20: Time-avg. temperature - S.S. - Case C1. 


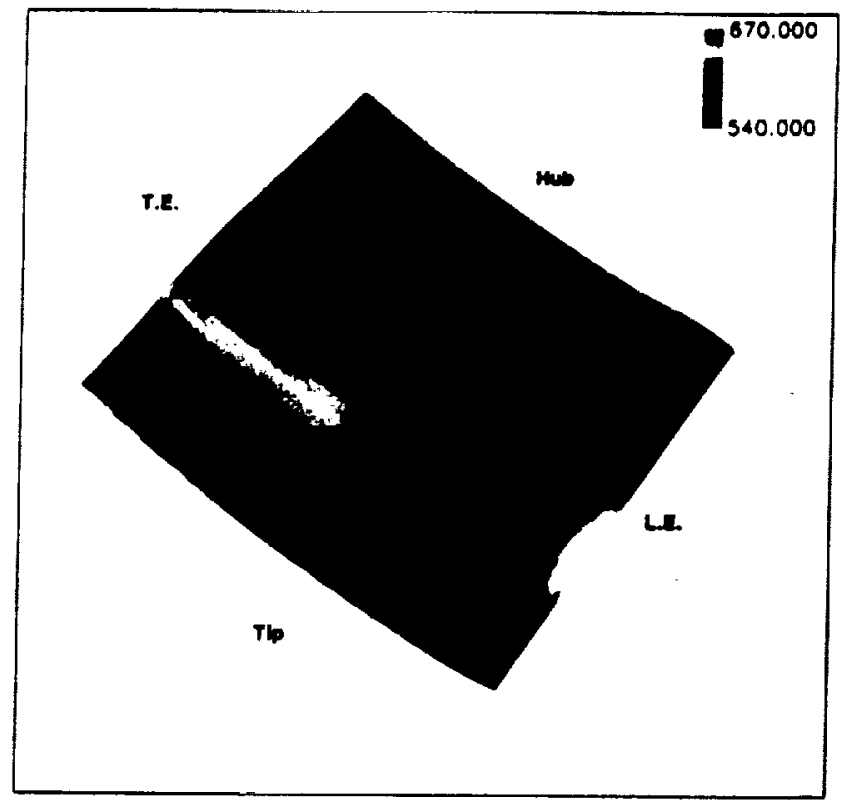

Figure 21: Time-avg. temperature - S.S. - Case C2.

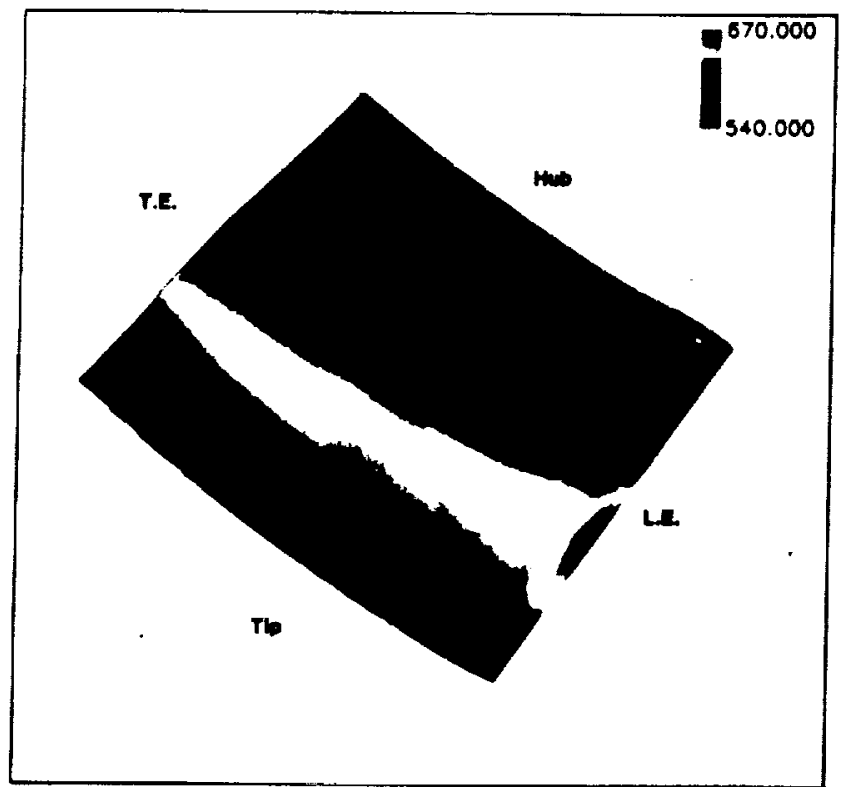

Figure 22: Time-avg. temperature - S.S. - Case C3.

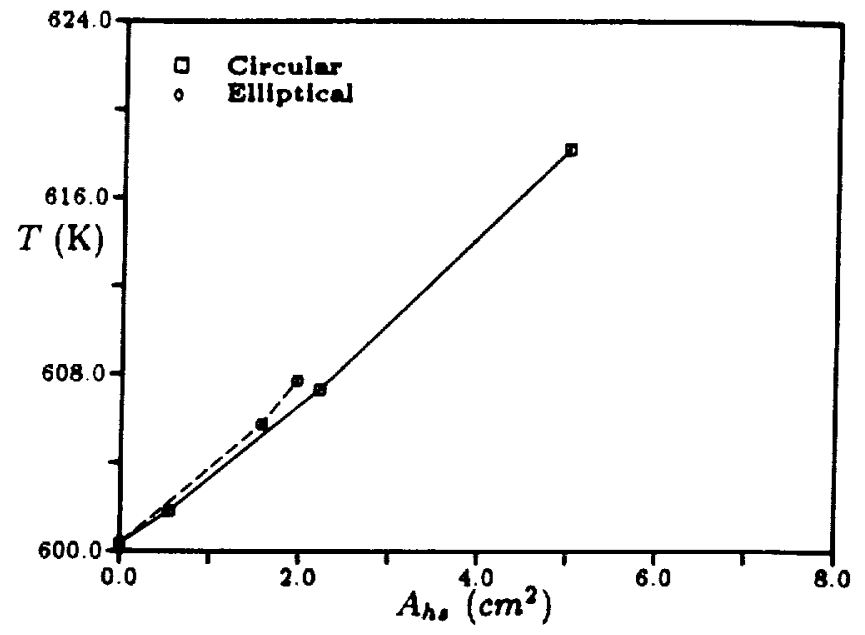

Figure 23: Integrated time-averaged rotor surface temperature as a function of hot streak area.

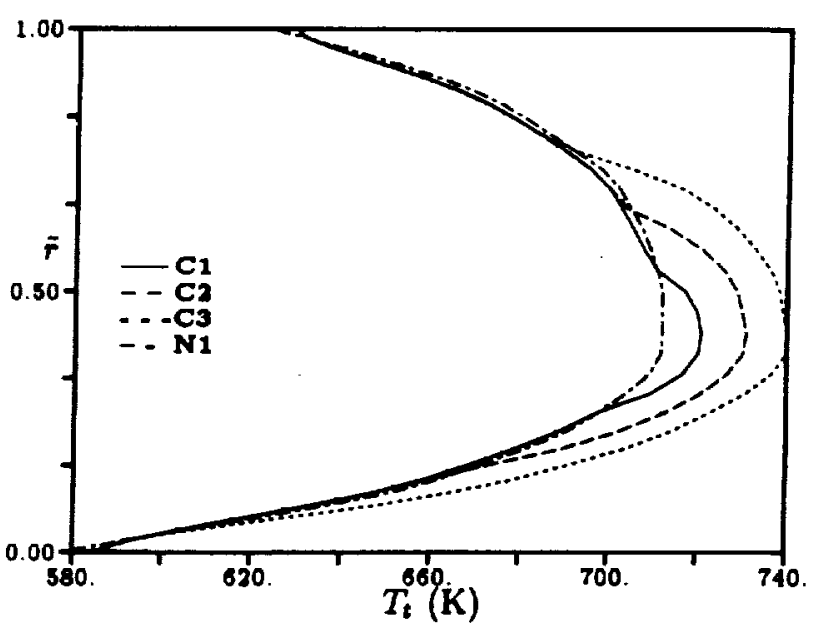

Figure 24: Total temperature distribution at the inlet of the vane. 


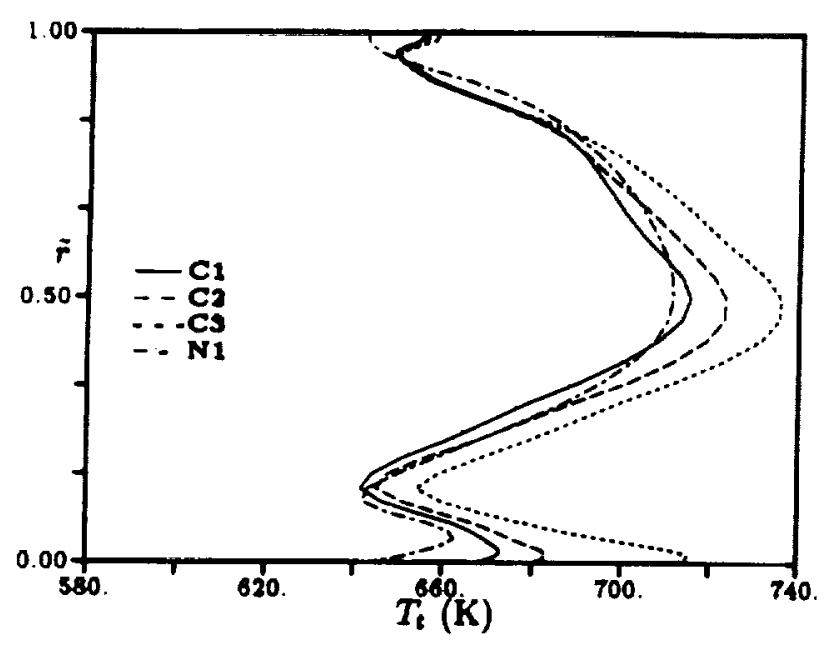

Figure 25: Total temperature distribution at the exit of the vane.

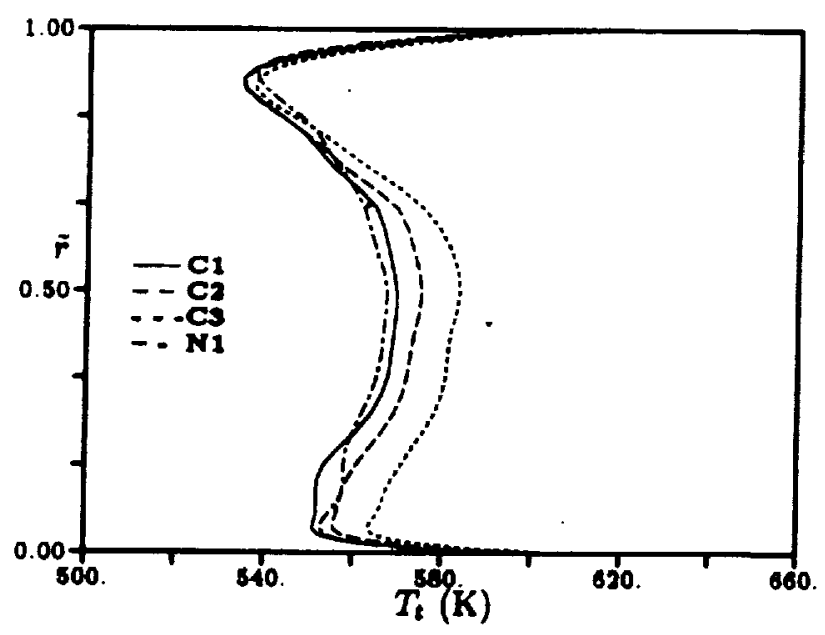

Figure 26: Total temperature distribution at the exit of the rotor.

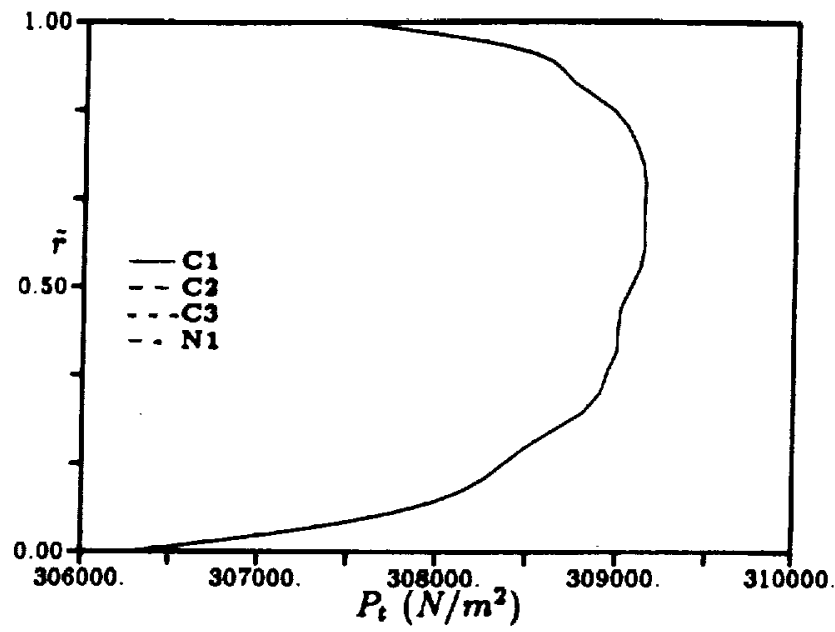

Figure 27: Total pressure distribution at the inlet of the vane.

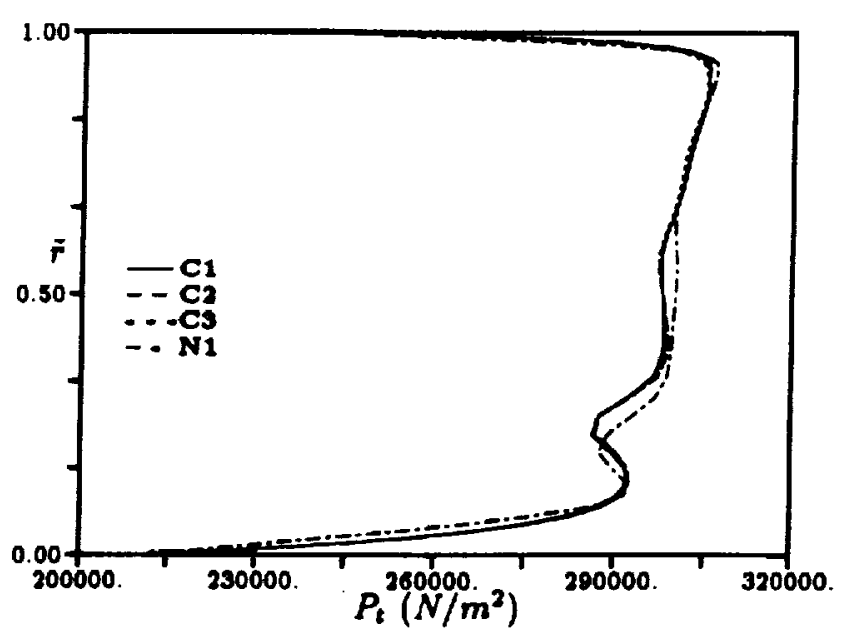

Figure 28: Total pressure distribution at the exit of the vane. 


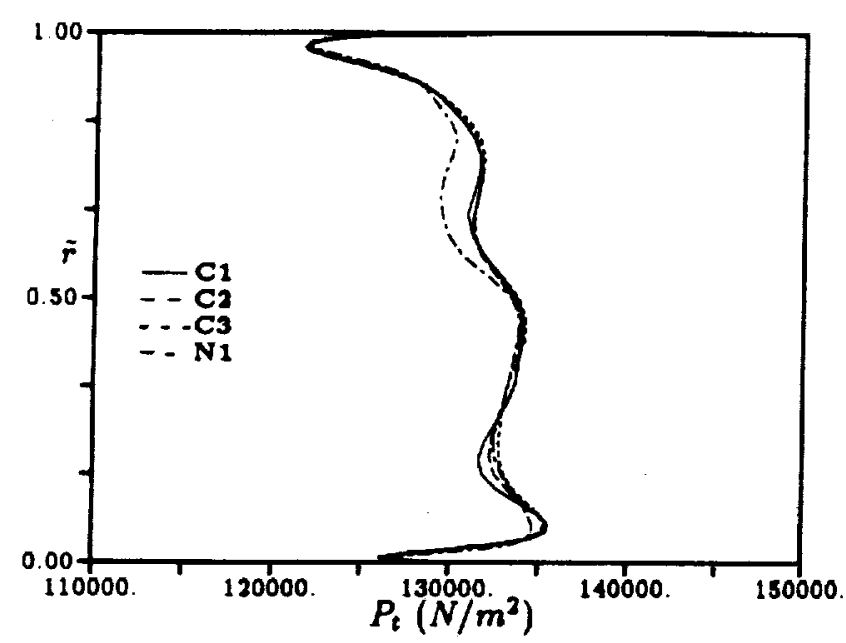

Figure 29: Total pressure distribution at the exit of the rotor.

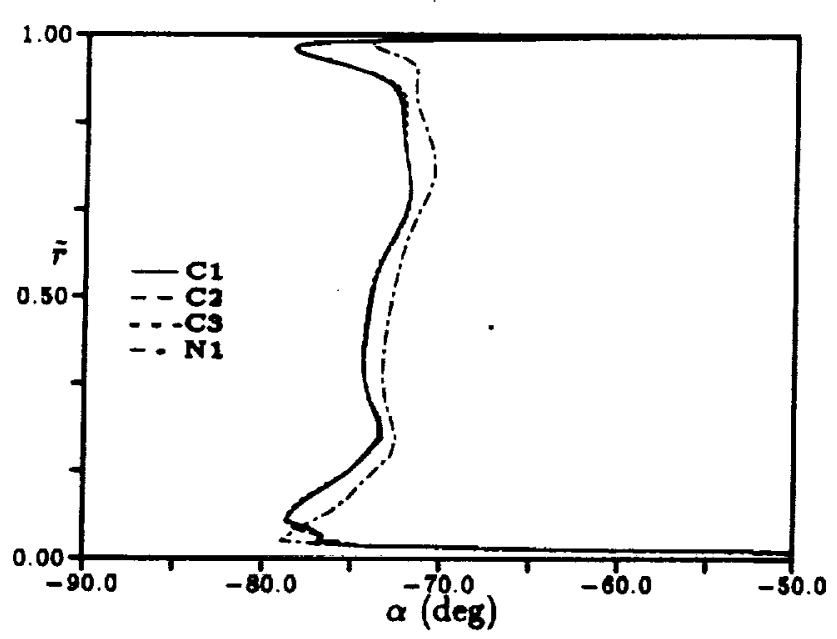

Figure 30: Circumferential absolute flow angle distribution at the exit of the vane.

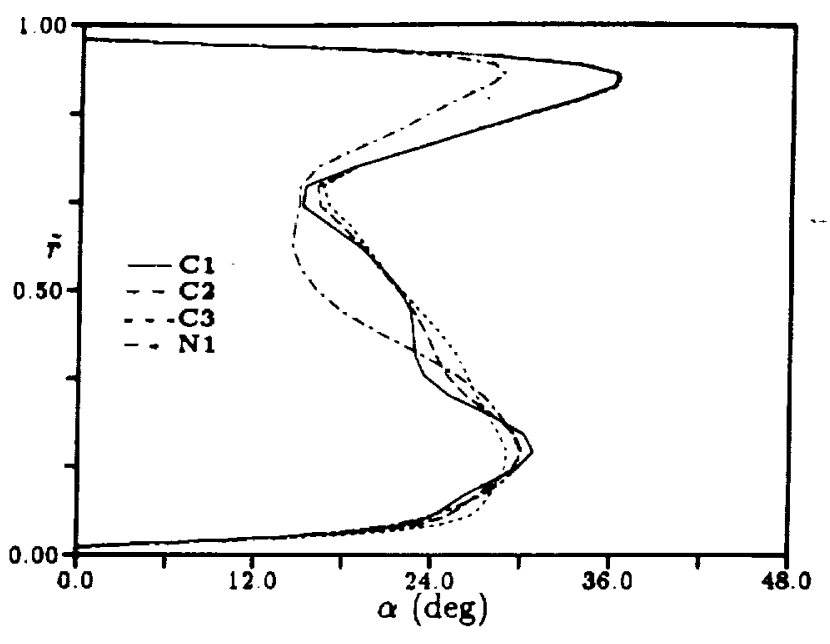

Figure 31: Circumferential absolute flow angle distribution at the exit of the rotor.

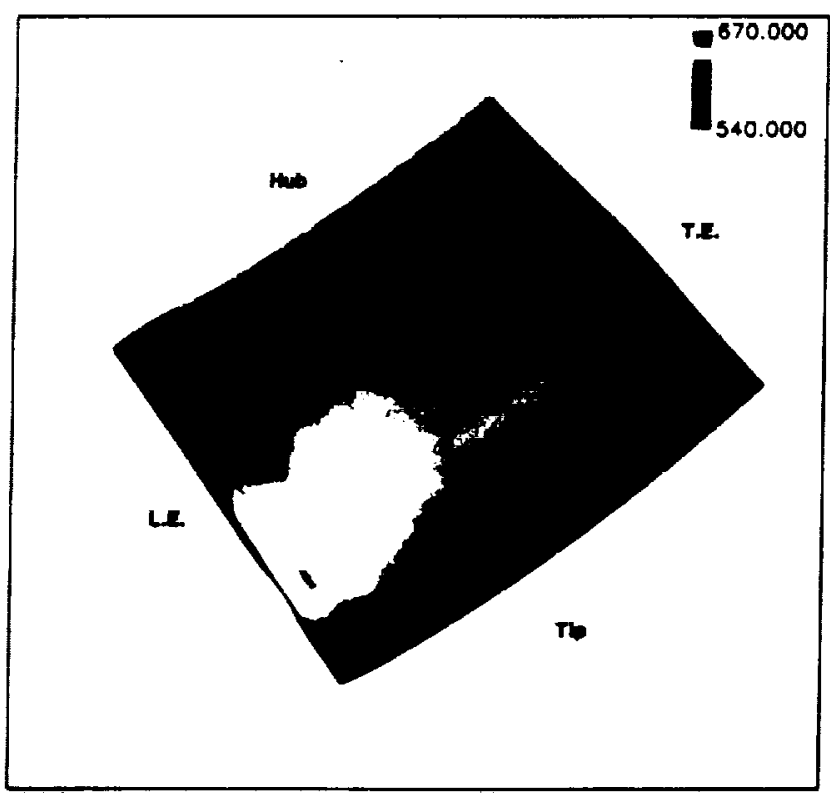

Figure 32: Time-avg. temperature - P.S. - Case E1. 


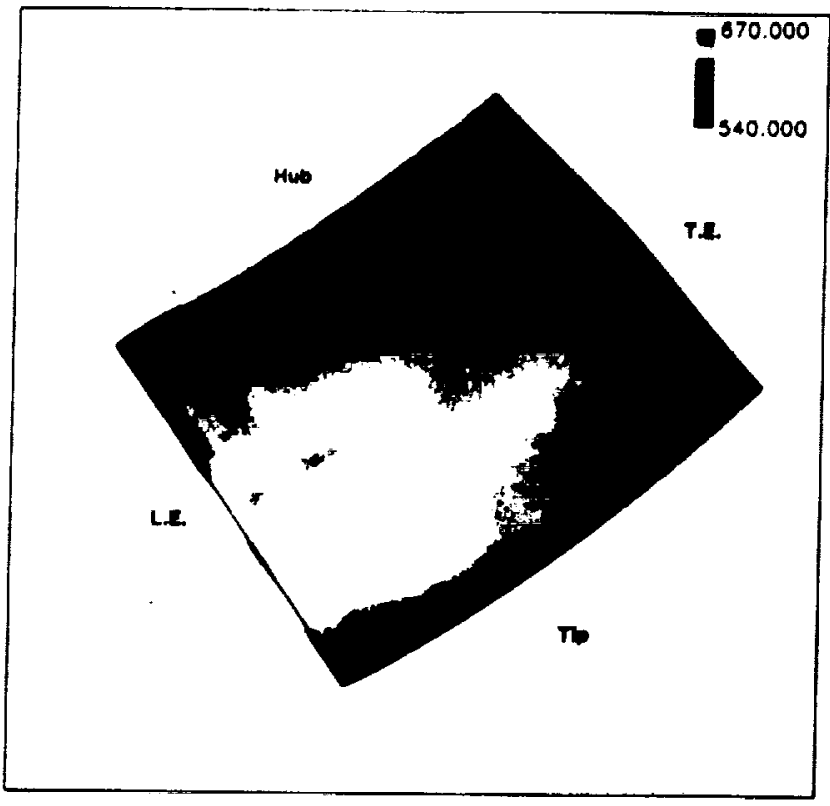

Figure 33: Time-avg. temperature - P.S. - Case E2.

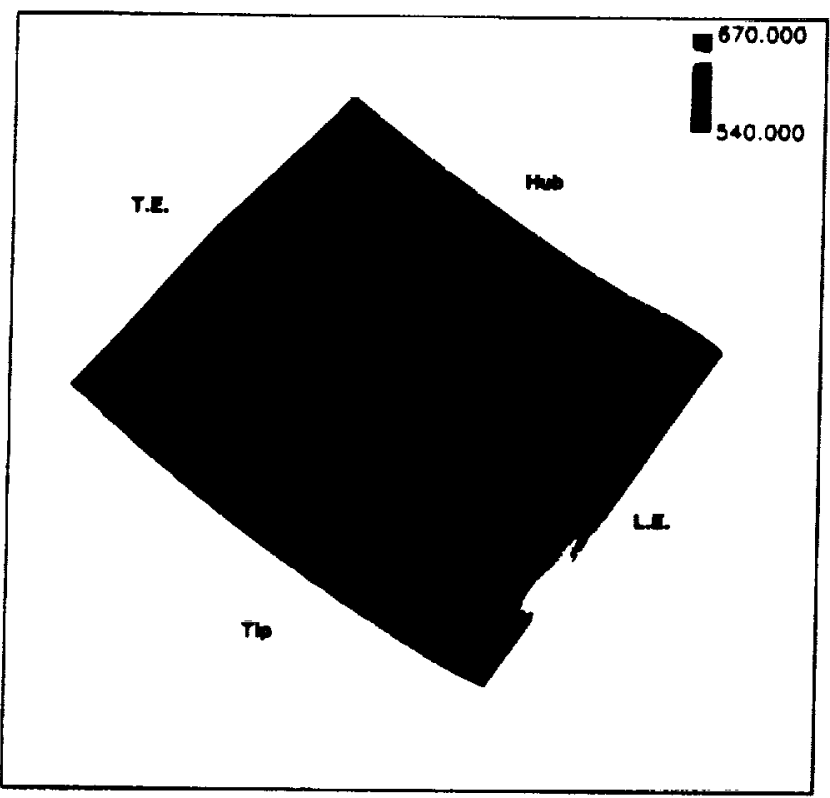

Figure 34: Time-avg. temperature - S.S. - Case E1.

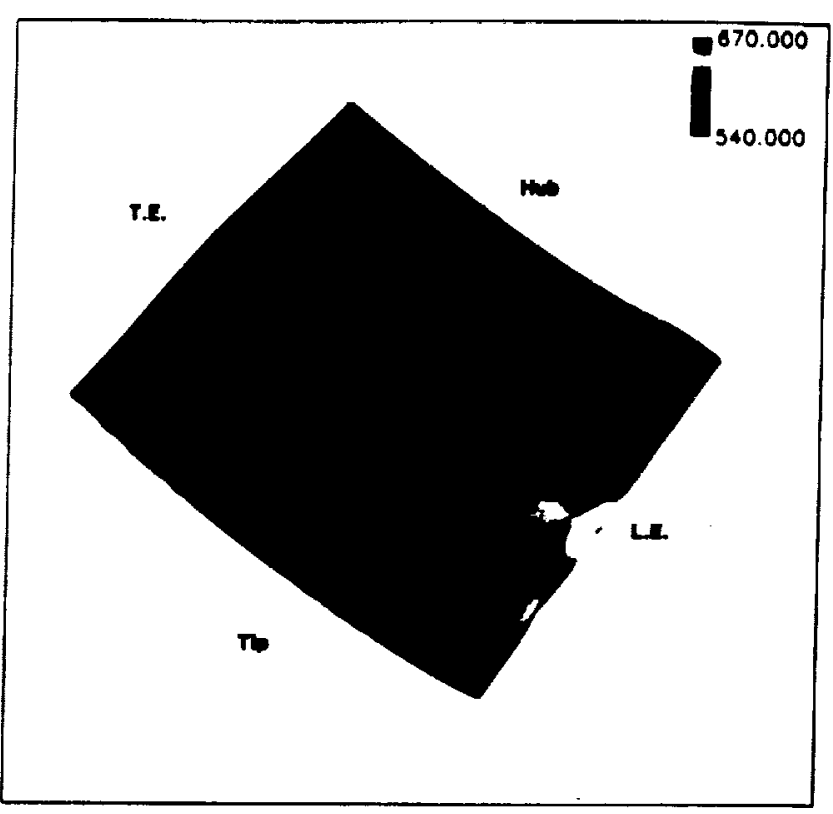

Figure 35: Time-avg. temperature - S.S. - Case E2.

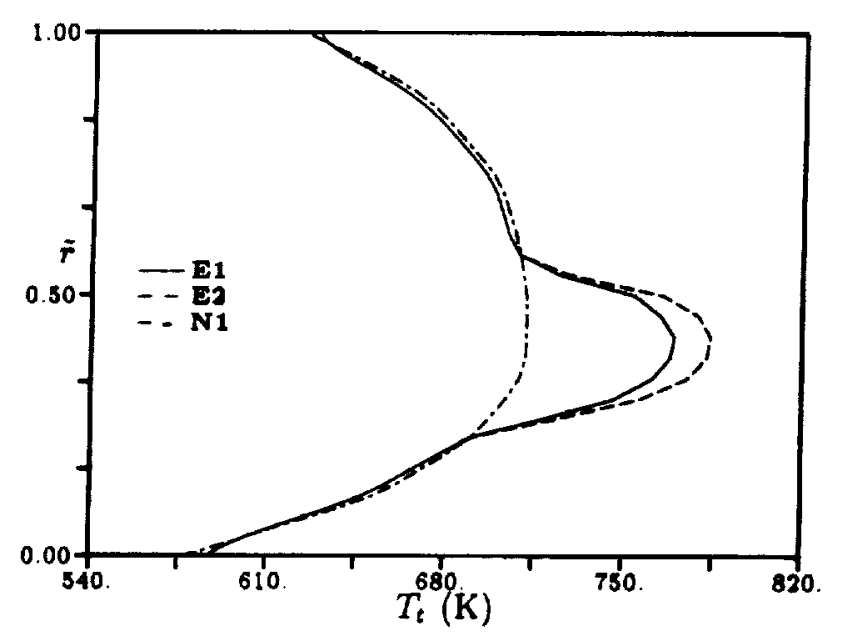

Figure 36: Total temperature distribution at the inlet of the vane. 


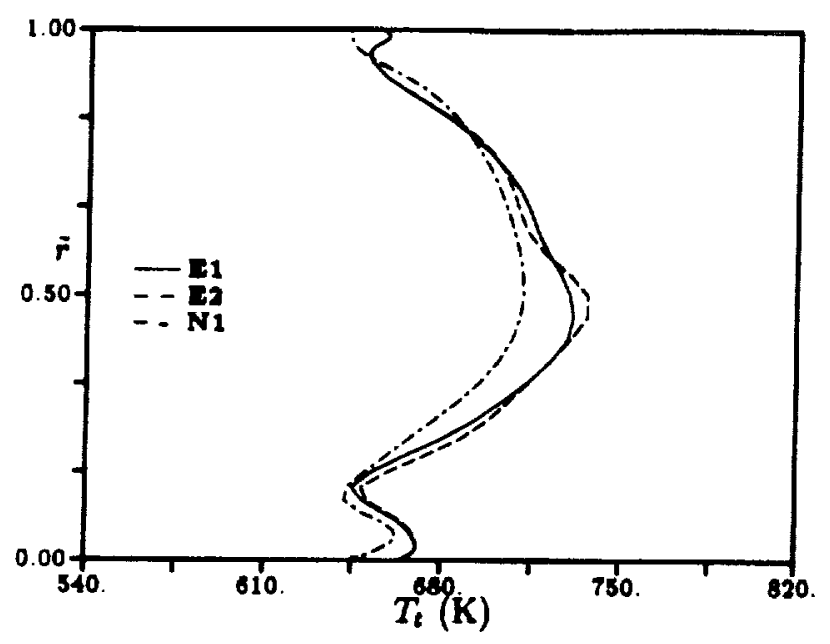

Figure 37: Total temperature distribution at the exit of the vane.

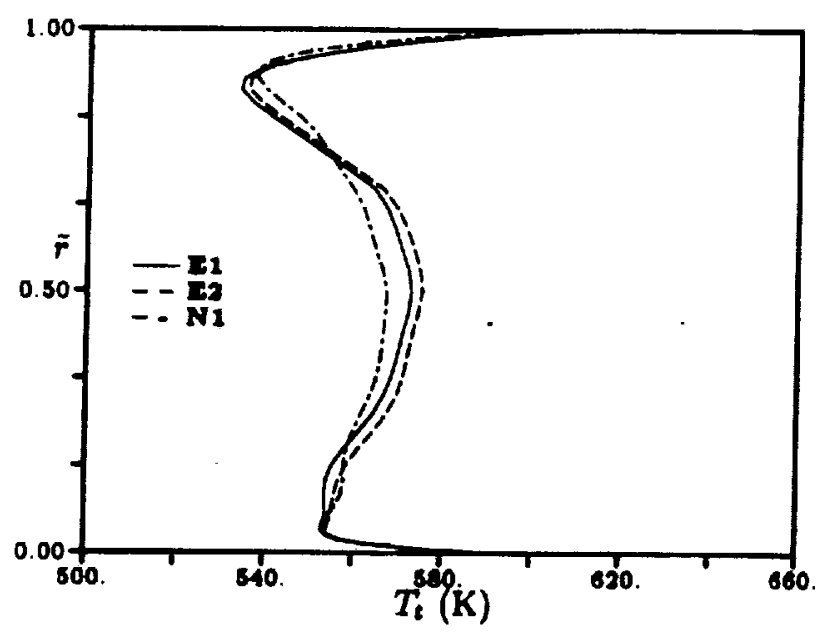

Figure 38: Total temperature distribution at the exit of the rotor.

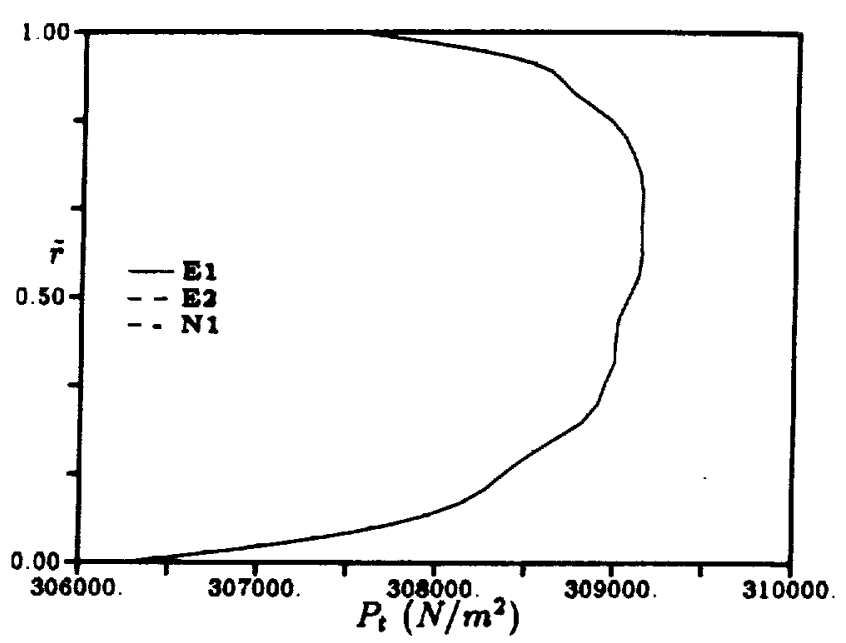

Figure 39: Total pressure distribution at the inlet of the vane.

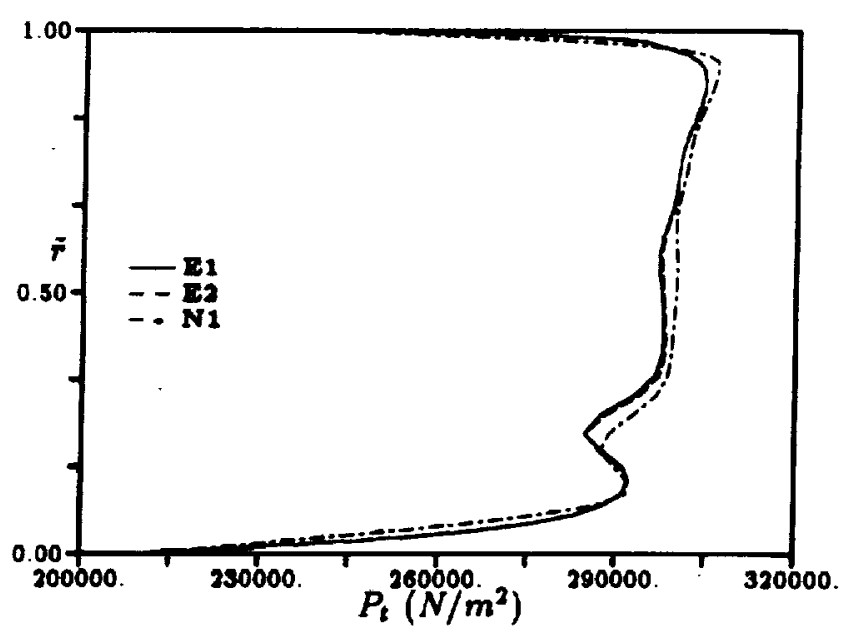

Figure 40: Total pressure distribution at the exit of the vase. 


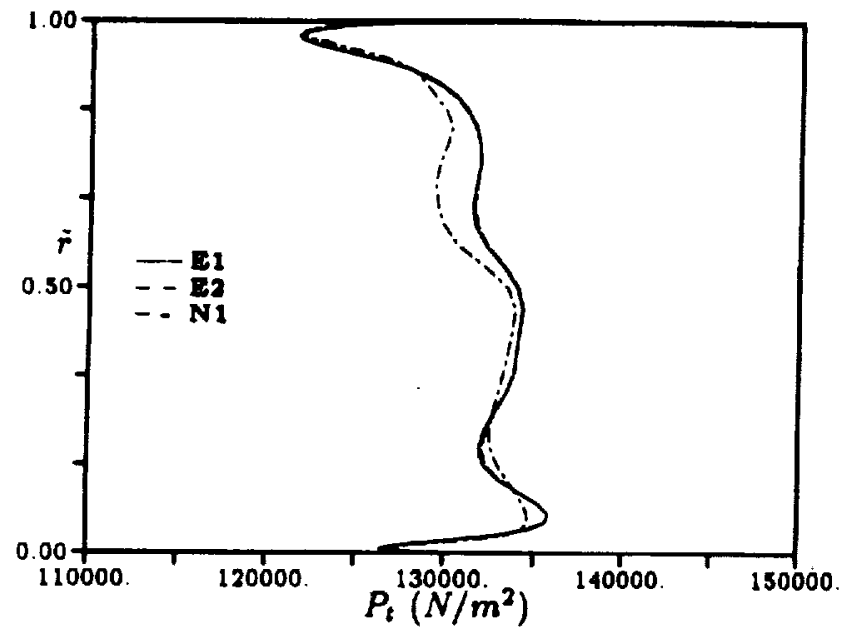

Figure 41: Total pressure distribution at the exit of the rotor.

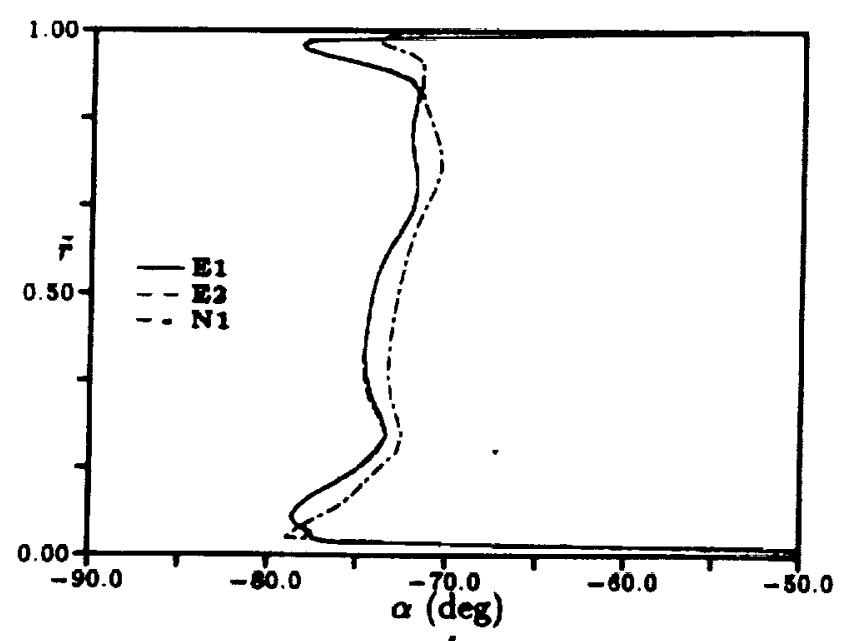

Figure 42: Circumferential aboolute flow angle distribution at the exit of the vane.

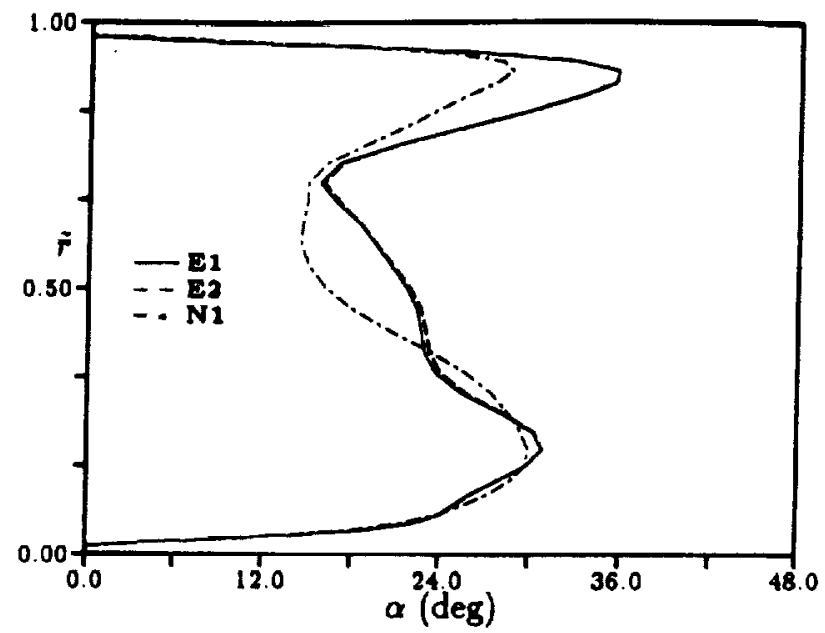

Figure 43: Circumferential aboolute thow angle distribution at the exit of the rotor. 